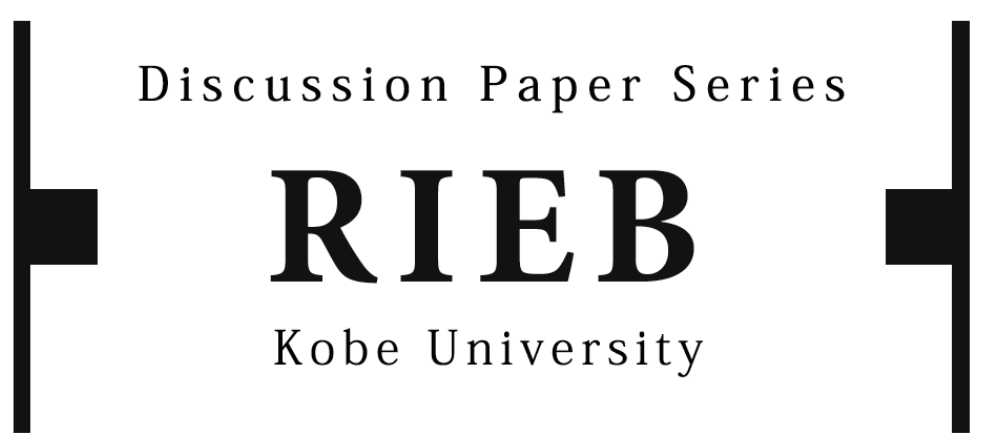

DP2013-28

Hometown-Specific Bargaining Power in an Experimental Market in China

\author{
Xiangdong QIN \\ Junyi SHEN \\ Ken-Ichi SHIMOMURA \\ Takehiko YAMATO
}

Revised January 8, 2016

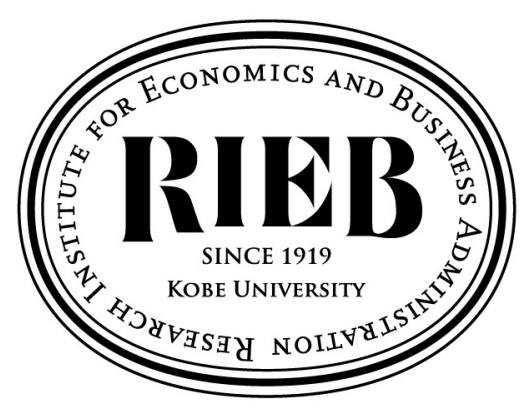

Research Institute for Economics and Business Administration Kobe University 


\title{
Hometown-specific Bargaining Power in an Experimental Market in China*
}

\author{
Xiangdong Qin ${ }^{\ddagger}$, Junyi Shen ${ }^{\dagger}$, \\ Ken-Ichi Shimomura ${ }^{\dagger}$ and Takehiko Yamato ${ }^{\#}$
}

January, 2016

\begin{abstract}
We conducted a market experiment in China to examine potential effects of subjects' hometowns on their behaviors as well as potential differences between team and individual trades. We observed that group size affected bargaining power and subsequently payoffs in different directions according to where the subjects were from. This finding suggests that it is important to take one's hometown into account when comparing economic behavior or decision-making between teams and individuals, especially in the countries or regions where hometown diversity plays a central role in explaining differences in business management and local market performance.
\end{abstract}

Keywords: Hometown, Market experiment, Team trade, Individual trade, China

JEL classifications: C91, C92, D51

\begin{abstract}
* We thank Tokinao Ohtaka, and Kiyotaka Takahashi for research assistance. Financial support from the Murata Science Foundation, and the Japanese Ministry of Education, Culture, Sports, Science and Technology through Grant-in-aid for Scientific Research 26285045 and Grant-in-aid for Scientific Research on Priority Areas 19046002 and 19046004 is gratefully acknowledged. Shimomura and Yamato thank Leeds University Business School for their hospitality during the period when this draft was written. All of the views expressed in this paper and any errors are the sole responsibility of the authors.
\end{abstract}

¥School of Economics, Shanghai Jiao Tong University, 535 Fa Hua Zhen Rd., Shanghai 200052, China.xdqin@sjtu.edu.cn

${ }^{\dagger}$ Research Institute for Economics and Business Administration, Kobe University, 2-1 Rokkodai, Nada, Kobe 657-8501, Japan. shen@rieb.kobe-u.ac.jp ken-ichi@rieb.kobe-u.ac.jp

\# Department of Social Engineering, Graduate School of Decision Science and Technology, Tokyo Institute of Technology, 2-12-1 Ookayama, Meguro-ku, Tokyo 152-8552, Japan. yamato@soc.titech.ac.jp

※Corresponding author. Email: xdqin@sjtu.edu.cn 


\section{Introduction}

Hometown diversity has played a central role in explaining differences in business management and local market performance within a country such as China. In China it is much easier for people to have good connections with those from the same hometown than with those from different hometowns. For example, Tsang (1998) mentioned in his study that similar to kinship, school, and place of work, hometown acts as a key aspect of personal identification to form a guanxi (i.e., relationship or connection in literal meaning), which is regarded as "the informal connections so essential to gaining approval for or access to just about everything in China”. In addition, Zhang (2001) proposed that "hometown connections" have played a critical role in explaining location choices of the foreign direct investments (FDI) by overseas Chinese in China, because the overseas Chinese not only share the same language and culture with people in their hometowns but also have relatives, friends, and former business ties in their hometowns.

In spite of the importance of hometown diversity, results from economic experiments are not always characterized in terms of hometowns of subjects because there is no hypothesis of behaviors or phenomena peculiar to hometowns in economic theory. Thus, the first purpose of the current study is to examine potential effects of subjects' hometowns (i.e., hometown diversity) on their experimental behaviors, specifically their bargaining power in the commodity exchange. To make the study simple, we divide subjects' hometowns into two categories - coastal and inland areas, because on the one hand there is an apparent time lag in economic development between coastal and inland areas in China, and on the other hand communication abilities are commonly considered to be different between people from coastal areas and people from inland areas. Regarding this issue, the evidence in the literature is extremely scarce.

The second purpose of this study is to examine potential differences between team and individual trades. A growing body of experimental research has recently investigated team or group decision-making and its possible differences from individual decision-making. Experimental evidences have shown that individual and team decisions differ in a broad range of economic situations (e.g., Bornstein and Yaniv, 1998; Cason and Mui, 1997; Copper and Kagel, 2005; Kocher and Sutter, 2005; kugler et al., 2007; Kocher et al., 2006; Sutter, 2005). In a recent survey paper, Charness and 
Sutter (2012) provided an excellent review on the issue of group decision-making. ${ }^{1}$ However, to the best of our knowledge, there are no economic evidences regarding the effect of group size on subjects' bargaining power in experimental markets, especially when hometown diversity is taken into account.

In order to examine the issues mentioned above, we apply a theoretical model that is an exchange economy with two types of consumers and two kinds of commodities in which three competitive equilibria exist. One type of consumers initially own the more of the first good, and the less of the second good, than the other type of consumers. The same type of consumers are all rationed identical commodity bundles of endowment. We choose the second good as the numeraire, the price of which is always fixed to be one, and focus on the behavior of the relative price of the first good. There are three equilibrium prices in our model. The lowest relative price is beneficial for the type of consumers having more of the second good, and the highest relative price is advantageous to the type of consumers having more of the first good. The intermediate price gives a "fairly equitable" allocation. The tatonnement dynamics predict that relative prices go up when the first good is excessively demanded, and go down when it is excessively supplied, in the market. Therefore, the relative prices observed in our experiment are served as an index of subjects' bargaining power.

According to the traditional economic theory, neither hometown diversity nor group size has an influence on subjects' bargaining power. However, in our market experiment, we found that group size affected bargaining power and subsequently payoffs in different directions according to where the subjects were from. In particular, increasing group size from one-person to two-person strengthened the bargaining power of subjects from coastal areas but weakened that of subjects from inland areas when commodity exchanges were conducted between subjects from different areas. This finding implies that it is important to take one's hometown into account when comparing economic behavior or decision-making between teams and individuals, especially in the countries or regions where hometown diversity plays a central role in explaining differences in business management and local market performance.

The problem of multiplicity of competitive equilibria in exchange economies with

\footnotetext{
1 Their main conclusions are that (i) groups are more cognitively sophisticated than individuals; (ii) groups can help with self-control and productivity problems; and (iii) groups may decrease welfare because of stronger self-interested preferences.
} 
two consumers and two goods has recently been investigated by using laboratory markets. Crockett et al. (2011) designed and conducted an experiment of the Gale's (1963) example of an exchange economy in the double auction institution using the MarketScape software. In the Gale model, there are three equilibria: two of them are "extreme" (the allocations are respectively supported by the price vectors $(1,0)$, and $(0$, 1)), and the other is an interior equilibrium. The Walrasian stability depends on the initial holdings of the consumers: the interior equilibrium is the only stable point in some cases, and it is unstable and the two extreme equilibria are stable in other cases. Crockett et al. (2011) observed surprisingly strong support for these predictions by the Walrarian stability theory. The methodology of our experiment is different from theirs: our institution is a manual experiment of trading in a pit market, while theirs is an on-line experiment of double auction.

Moreover, Huber et al. (2009) implemented an experiment of the Shapley-Shubik's (1997) example of an exchange economy. In the Shapley-Shubik model, there are three equilibria which are all interior, the intermediate equilibrium is unstable, and the two other equilibria are unstable. Their data shows that there is a tendency that allocations converge to the intermediate equilibrium in the Edgeworth box. The experimental methodology in Huber et al. (2009) is also different from ours. They used computers for the subjects to submit their proposals of trades and to decide whether to accept others' offers or not only once in a period. The subjects carried over their holdings from the end of one period to the beginning of the next period until the end of one session of trade periods. On the other hand, we told subjects to trade face-to-face and reset holdings to the initial state at the beginning of every trading period in our experiment of trading in a pit market. We also compared the cases of individual and team decisions and consider subjects' hometowns in the context of a market experiment, while the above mentioned literature focuses on individual decisions only without investigating either team decisions or subjects' hometown effects.

The remainder of the paper is organized as follows. Section 2 presents the theoretical model that we applied to conduct our experiment. In Section 3, we explain the design and procedures of our experiment. Sections 4 and 5 provide the results of the experiment and the discussions of the results, respectively. Finally, concluding remarks are made in Section 6.

\section{Theoretical Model}


We consider an exchange economy model with two kinds of private goods called $X$ and $Y$ and two types of consumers named 1 and $2 .^{2}$ The utility functions of consumers 1 and 2 are of the "Leontief-nested" type in the following forms:

$$
\begin{aligned}
& U_{1}\left(x_{1}, y_{1}\right)=a_{1} \min \left[g_{1}\left(x_{1}\right), y_{1}\right]+b_{1} \text { and } \\
& U_{2}\left(x_{2}, y_{2}\right)=a_{2} \min \left[g_{2}\left(x_{2}\right), y_{2}\right]+b_{2}
\end{aligned}
$$

In the experiment, we set $a_{1}=52.58, b_{1}=669.96, a_{2}=50, b_{2}=695.07$,

$$
\begin{aligned}
g_{1}\left(x_{1}\right) & =x_{1} / 9.8 & & \text { if } \quad x_{1} \in[0,6.2] \\
& =10 x_{1}-6.2(10.5-1 / 9.8) & & \text { if } \quad x_{1} \in[6.2,7.5] \\
& =x_{1} / 9.8+1.3(10.5-1 / 9.8) & & \text { if } \quad x_{1} \in[7.5,14.9] \\
& =10.5 x_{1}-13.6(10.5-1 / 9.8) & & \text { otherwise; } \\
g_{2}\left(x_{2}\right) & =x_{2} / 9.1 & & \text { if } x_{2} \in[0,7.35] \\
& =11.3 x_{2}-7.35(11.3-1 / 9.1) & & \text { if } \quad x_{2} \in[7.35,8] \\
& =x_{2} / 9.1+0.65(11.3-1 / 9.1) & & \text { if } \quad x_{2} \in[8,17.45] \\
& =11.3 x_{2}-16.8(11.3-1 / 9.1) & & \text { if } \quad x_{2} \in[17.45,18.45] \\
& =x_{2} / 9.1+1.65(11.3-1 / 9.1) & & \text { otherwise. }
\end{aligned}
$$

The individual endowment of consumer 1 is given by $\left(\bar{x}_{1}, \bar{y}_{1}\right)=(25,1)$ and the individual endowment of consumer 2 is $\left(\bar{x}_{2}, \bar{y}_{2}\right)=(5,29)$.

Figure 1 displays this economy in an Edgeworth box. Notice that the utility functions satisfy local nonsatiation ${ }^{3}$, and are maximized by a unique point on the budget line for any positive prices. Then, the solid (resp. dashed) piecewise linear line denotes consumer 1's (resp. consumer 2's) “offer curve,” derived by varying prices and asking the consumer how many units of commodities she would like to trade to maximize her utility at each price. Notice that the offer curves are given by $y_{1}=g_{1}\left(x_{1}\right)$ and $y_{2}=g_{2}$ $\left(x_{2}\right)$, because the utility maximization points are the loci of the verteces of the L-shaped indifference curves. There are three competitive equilibrium allocations, A, B, and C, indicated by the points of intersection of the two offer curves.

\footnotetext{
2 We give formal definitions of concepts in an exchange economy model in Appendix 1.

${ }^{3}$ The utility function $U_{0}$ defined over $R_{+}^{2}$ satisfies local nonsatiation if, for every $\left(x_{0}, y_{0}\right) \in$ $R_{+}^{2}$ and for every $\varepsilon>0$, there exists $\left(x_{0}^{\prime}, y_{0}^{\prime}\right) \in R_{+}^{2}$ such that $\left\|\left(x_{0}^{\prime}, y_{0}^{\prime}\right)-\left(x_{0}, y_{0}\right)\right\|<\varepsilon$ and $U_{0}\left(x_{0}^{\prime}, y_{0}^{\prime}\right)>U_{0}\left(x_{0}, y_{0}\right)$.
} 
We next consider Walrasian dynamics of price adjustment process, which works off equilibrium in the market. Let $p=P x / P y$ be the price of good $X$ relative to good $Y$. Figure 2 represents a diagram of the excess demand function for good $X$ which is derived from our two-good economy model. ${ }^{4}$ The characteristic of this excess demand function is to have three equilibrium prices at which excess demand is equal to zero: A (0.4449), B (1.0582), and C (2.1147). According to Walrasian dynamics of price adjustment process, if the relative price of $X, p$, is smaller than A (larger than $\mathrm{C}$ ), the value of excess demand for $X$ is positive (negative), so that $p$ increases (decreases). If $p$ lies between $\mathrm{A}$ and $\mathrm{B}$ (between $\mathrm{B}$ and $\mathrm{C}$ ), the value of excess demand is negative (positive), so that $p$ decreases (increases). Therefore, the equilibrium price $\mathrm{B}$ is locally unstable, whereas the other two prices $\mathrm{A}$ and $\mathrm{C}$ are both locally stable. ${ }^{5}$

Figure 1 shows the three equilibrium allocations, $\mathrm{A}, \mathrm{B}$, and $\mathrm{C}$, which respectively associate with the equilibrium prices. The intermediate equilibrium allocation associated with $\mathrm{B}=(12.0132,14.7432)$, indicated in terms of agent 1 's consumption bundle, is supported by a locally unstable equilibrium price, and the other two equilibrium allocations corresponding to $A=(6.99771,9.00859)$ and $C=(15.4803$, 21.1309) are attained with locally stable equilibrium prices. Figure 1 can be also regarded as demonstrating symmetric equilibrium outcomes in a market with $n$ traders on each side when all traders of the same type take the same action.

$<$ Insert Figure 2 here $>$

In our experiment, subjects chose integers as trading units, not real numbers as in the theory. Therefore, it is important to consider a discrete version of the exchange economy corresponding to the experimental setting to make a rigorous theoretical prediction. Figure 3 shows this discrete exchange economy in an Edgeworth box. The locus of marks (resp. ' marks) denotes consumer 1's (resp. consumer 2's) offer

\footnotetext{
${ }^{4}$ We only need to focus on trades of good $X$ because, based on the Walras' law, the market of good $X$ is clear when that of good $Y$ is clear. Notice that Walras' law holds in our model since the utility functions of all consumers satisfy local nonsatiation.

${ }^{5}$ See Appendix 1 for the formal definitions of local stability and instability of equilibrium according to Walrasian price adjustment process.
} 
curve, which is thick, in the discrete economy. The two offer curves intersect at seven points indicating competitive equilibria: $\mathrm{A} 1=(7,8), \mathrm{A} 2=(7,9), \mathrm{A} 3=(8,9), \mathrm{C} 1=(16$, $20)$, and $C 2=(16,21)$ give locally stable equilibria together with the corresponding equilibrium price ratios $p=0.39,0.44,047,2.11,2.22$, respectively, while $\mathrm{B} 1=(12$, $15)$ and B2 $=(12,16)$ are locally unstable points with $p=1.08,1.15$, respectively. ${ }^{6}$

$<$ Insert Figure 3 here $>$

Moreover, we prohibited subjects from trading commodities at which the price ratio $p$, the trading ratio of $\mathrm{Y}$ to $\mathrm{X}(=($ Amount of $\mathrm{Y}) /($ Amount of $\mathrm{X}))$, was less than $1 / 4$ $=0.25$. For $p<1 / 4$, there are several competitive equilibria other than the above seven equilibria. In Figure 3, we omit these equilibria and focus on the seven equilibria close to the three equilibria in Figure 1 of the usual Edgeworth box.

Table 1 summarizes the equilibrium predictions. There are trade-offs between stability and "equity" of the competitive equilibria. The equilibria A1, A2, and A3 with low relative prices $p$ are beneficial for the consumer of type 2 who initially had more of commodity $Y$, while the equilibria $\mathrm{C} 1$ and $\mathrm{C} 2$ with high relative prices of commodity $X$ is advantageous to the consumer of type 1 who initially had more of commodity $X$. These four equilibria are locally stable, but not equitable. On the other hand, the equilibria B1 and B2 with intermediate prices give allocations that generate the minimal difference between the payoffs to the two types of consumers. We say that the equilibrium and allocation are fair. In particular, each type of consumer receives the same equilibrium payoff at B1. However, they are locally unstable.

Considering the relation between the above predicted equilibria and the consumers' bargaining power, we say that any relative price $p<1.08$, which includes the equilibria $\mathrm{A} 1, \mathrm{~A} 2$, and A3 but not B1, B2, C1, or C2, indicates that the consumer of type 2 has a relatively higher bargaining power than the consumer of type 1 . In contrast, any relative

\footnotetext{
${ }^{6}$ The number of competitive equilibria when only integer units are allowed in trading in experimental settings could be quite larger than that when trading units are real numbers in theory. For Shapley-Shubik (1977) exchange economy with two goods, there are only three competitive equilibria in theory. However, there are 198 equilibria with only integer trading units and no trading price constraint (see Masui et al. (2010) for detailed results).
} 
price $p>1.15$, which includes the equilibria $\mathrm{C} 1$ and $\mathrm{C} 2$ but not $\mathrm{A} 1, \mathrm{~A} 2, \mathrm{~A} 3, \mathrm{~B} 1$, or B2, indicates that the consumer of type 1 has a relatively higher bargaining power than the consumer of type 2. Finally, bargaining powers of the consumers of both types are almost the same when the relative price $p$ lies between the middle equilibria B1 (1.08) and B2 (1.15).

$<$ Insert Table 1 here $>$

\section{Experimental Design and Procedure}

There were two treatments in our experiment, one was the individual treatment and the other was the team treatment. Both treatments shared basically the same design and procedures other than that in the individual treatment subjects were individuals, whereas in the team treatment subjects were teams of two subjects each. In the latter case the two subjects were seated together to discuss their trading strategies. In order to keep per capita incentives constant across treatments, we paid each member of a team the same amount that the team obtained from the experiment.

Each treatment consisted of four sessions, which the four sessions were based on consumers' type (type 1 or type 2) and subjects' hometown (coastal or inland areas). That is to say that in each treatment we used a $2 \times 2$ design, hence, eight sessions in total were conducted. Table 2 provides the information on the time schedule and number of subjects in each session. We conducted all the sessions at Shanghai Jiao Tong University on September 21 and 22 of 2011 using paper and pencils. A total of 144 undergraduate students participated in the experimental sessions, 48 in the individual treatment and 96 in the team treatment. Among them, the hometowns of half of the subjects locate in the coastal areas and the others locate in the inland areas. In each session of the individual (resp. team) treatment, 6 (resp. 12) subjects played the role of type 1 and 6 (resp. 12) subjects did the role of type 2 . Their roles were fixed throughout the experiment.

$<$ Insert Table 2 here $>$

In each session of the team treatment, each team of two subjects received two 
experimental instructions, one record sheet, one payoff table and two name tags. ${ }^{7}$ The name tag of each subject indicated her team name (A, B, C, .., or L) and her identification number (1 or 2$)$. Six teams (A-F) played the role of type 1 , and six teams (G-L) played the role of type 2. Each team was given pink cards and/or white cards in an envelope. One pink card was one unit of commodity $\mathrm{X}$, and one white card was one unit of commodity Y. We explicitly noticed to every subject that she was not allowed to reveal any information regarding her team payoff table or endowed color cards to any other team.

The subjects of each team walked around a relatively large laboratory room and found a team to trade. We prohibited any team from trading any amount of commodity $\mathrm{X}$ or $\mathrm{Y}$ more than what they held. In addition, as explained in the previous section, the trading ratio of $\mathrm{Y}$ to $\mathrm{X}$ should be greater than or equal to $1 / 4=0.25$ to exclude undesirable equilibrium allocations.

We told the subjects to trade commodity $\mathrm{X}$ for $\mathrm{Y}$ or $\mathrm{Y}$ for $\mathrm{X}$ when two teams reached an agreement. After writing the trading results in their record sheets, the teams reported them to the experimenter. The following information on the results was entered into the computer and displayed publicly through a projector: the team name giving commodity $\mathrm{X}$, the amount of the traded $\mathrm{X}$, the team name giving $\mathrm{Y}$, the amount of the traded $\mathrm{Y}$, and the trading ratio of the commodities (= $\mathrm{Y} / \mathrm{X})$. This was the end of one trade. The teams had 10 minutes for each period and they were allowed to trade as many times as they wanted within the time limit. For the next trading partner, the teams could choose any team as they wanted. That is to say that the next partner might be the same as or different from one of the teams they had already traded. After each period, the subjects went back to their seats and the experimenter collected all commodity cards. This was the end of one period.

At the beginning of the next period, the teams received the same materials as those of the previous period. In particular, holdings of commodities were reset at the end of the previous period and each team held the same endowment as that at the beginning of the previous period. After a 2-minute break, the next period started. One session had 5 periods, which means that the above steps were repeated 5 times.

The design and procedures in each session of the individual treatment were

7 The experimental instruction and payoff tables are provided in Appendixes 2 and 3. 
basically the same as those in the team treatment except that: (i) each subject received one experimental instruction, one record sheet, one payoff table and one name tag; and (ii) the name tag of each subject only indicated her ID name (A, B, C, .., or L).

Earnings of each subject or team depended on the final payoff that she or her team earned in one randomly selected period from the experiment. This period was chosen by a random device after the experiment. Each member of the same team received the same earnings. Sessions lasted about 1.5 hours. The average payoff per subject was $92.5 \mathrm{CNY}$ (about 14.2 USD if $1 \mathrm{USD}=6.5 \mathrm{CNY}$ ).

\section{Experimental Results}

\subsection{Trading Ratio of $Y$ to $X$}

Figure 4 plots the trading ratio of $\mathrm{Y}$ to $\mathrm{X}$ in each session. The three equilibria (i.e., the low, middle, and high equilibria) are also presented by the orange, red, and green lines, respectively. As shown in the figure, a certain level of fluctuation in the trading ratios can be observed in the early periods of the experiment, while with the passing of trading periods the fluctuation diminishes and most of the trading ratios lie within the interval of the low and middle equilibria and never reach the high equilibrium. Results of both the Wilcoxon sign-rank test and t-test suggest that in all the sessions except Inland2-Coast2 (i.e., team Inland-Coast session) the trading ratio of $\mathrm{Y}$ to $\mathrm{X}$ is statistically higher than the low equilibrium and lower than the middle equilibrium in the final period (i.e., period 5), which implies that the trading ratio does not converge to any equilibrium. In the session of Inland2-Coast2, the trading ratios of $\mathrm{Y}$ to $\mathrm{X}$ from period 2 to 5 are not significantly different from that at the low equilibrium, implying convergence to the low equilibrium ( $p$-value $=0.3173$ in Wilcoxon sign-rank test and $p$-value $=0.1387$ in t-test for period 5 ).

$<$ Insert Figure 4 here $>$

A detailed description of mean trading ratios of $\mathrm{Y}$ to $\mathrm{X}$ in each round of eight sessions is presented in Table 3. Over all, it seems that the mean trading ratio differs according to the subjects' hometowns (represented by sessions of Coast-Coast, Inland-Inland, Coast-Inland, and Inland-Coast) and/or group size (Individual or Team) 
but varies not too much across periods in each session. This is confirmed by the results of a two-way analysis of variance (ANOVA) that both the main and interaction effects of group size and subjects' hometown are significant in each period. ${ }^{8}$

<Insert Table 3 here>

In order to investigate how group size and subjects' hometown affect trading ratios, we ran the Wilcoxon rank sum test by comparing trading ratios of individuals with those of teams in the corresponding sessions. The results are displayed in Table 4. As shown in the table, except for Coast-Coast session the trading ratios of $\mathrm{Y}$ to $\mathrm{X}$ in the other three sessions are significantly different between the individual and team treatments in all periods. More specifically, the trading ratios of individuals are lower than those of teams in Coast-Inland session and the trading ratios of individuals are higher than those of teams in Inland-Coast and Inland-Inland sessions. ${ }^{9}$ Summing up the above evidences, we obtain the following results.

RESULT 1a. When commodity exchanges were conducted among subjects from different areas, group size matters significantly in terms of trading ratios, however, this effect went into different directions according to where the subjects are from. When the subjects of type 1 were from coastal areas, increasing group size from one to two raised the trading ratios. In contrast, when the subjects of type 1 were from inland areas, increasing group size from one to two lowered the trading ratios.

$8 F$ statistics and $p$ values in each period are as follow. For the main effect of group size, $F(1,93)=$ 4.75, $p=0.0318$ in period $1, F(1,101)=5.39, p=0.0222$ in period $2, F(1,96)=8.67, p=0.0041$ in period 3, $F(1,74)=10.12, p=0.0021$ in period 4 , and $F(1,66)=5.36, p=0.0237$ in period 5. For the main effect of subjects' hometown, $F(3,93)=2.85, p=0.0441$ in period $1, F(3,101)=3.98, p=$ 0.0101 in period 2, $F(3,96)=8.26, p=0.0001$ in period $3, F(3,74)=11.30, p=0.0000$ in period 4 , and $F(3,66)=16.10, p=0.0000$ in period 5 . For the interaction effect of group size and subjects' hometown, $F(3,93)=3.03, p=0.0332$ in period $1, F(3,101)=11.47, p=0.0000$ in period $2, F(3$, $96)=8.26, p=0.0001$ in period $3, F(3,74)=15.77, p=0.0000$ in period 4 , and $F(3,66)=17.03, p$ $=0.0000$ in period 5 .

9 We also ran twelve pairwise comparisons of the trading ratios among sessions separated by individual and team (i.e., Coast1-Coast1 versus Inland1-Inland1, Coast1-Coast1versus Coast1-Inland1, Coast1-Coast1 versus Inland1-Coast1, Inland1-Inland1 versus Coast1-Inland1, Inland1-Inland1 versus Inland1-Coast1, Coast1-Inland1 versus Inland1-Coast1, Coast2-Coast2 versus Inland2-Inland2, Coast2-Coast2 versus Coast2-Inland2, Coast2-Coast2 versus Inland2-Coast2, Inland2-Inland2 versus Coast2-Inland2, Inland2-Inland2 versus Inland2-Coast2, Coast2-Inland2 versus Inland2-Coast2). The Wilcoxon rank sum test results provide a similar image to that we obtained from Table 4. Therefore, for the sake of conserving space we omit these results and make them available upon request. 
RESULT 1b. When commodity exchanges were conducted among subjects from the same areas, whether or not group size matters significantly in trading ratios depended on where the subjects are from. When the subjects of both types were from coastal areas, increasing group size from one to two did not matter significantly in the trading ratios. When the subjects of both types were from inland areas, increasing group size from one to two significantly lowered the trading ratios.

$<$ Insert Table 4 here $>$

\subsection{Payoff}

Figures $5 \mathrm{a}$ and $5 \mathrm{~b}$ provide the basic information about subjects' payoffs. As shown in Figure 5a, it seems that the mean payoffs of subjects including both types differ very little among different sessions and treatments. However, if we separate subjects' payoffs by their types, we observe a different pattern. Figure 5b plots subjects' average payoffs per period in each session. The horizontal and vertical axes are for the payoffs of types 1 and 2, respectively. The 45-degree line is drawn here to help understanding which type of subjects earned more on average in each session. It is clear from the figure that except for one session (i.e., individual Inland-Inland) the subjects of type 2 earned more than those of type 1 did in the other seven sessions. This observation tells us that the payoffs earned in our market experiments may depend strongly on subjects' type. A three-way ANOVA of three factors (i.e., group size, subjects' hometown, and subjects' type) on subjects' payoffs suggests that although the main and interaction effects of group size and subjects' hometown are not significant, the main effect of subjects' type, the interaction effect of group size and subjects' type, the interaction effect of subjects' hometown and subjects' type, and the interaction effect of all the three factors are all strongly significant. ${ }^{10}$

\section{$<$ Insert Figure 5a here $>$ \\ $<$ Insert Figure 5b here $>$}

\footnotetext{
${ }^{10} F$ statistics and $p$ values are as follow. For the main effect of group size, $F(1,80)=0.52, p=$ 0.4719 , for the main effect of subjects' hometown, $F(3,80)=0.63, p=0.5971$, for the main effect of subjects' type, $F(1,80)=170.31, p=0.0000$, for the interaction effect of group size and subjects' hometown, $F(3,80)=0.52$, $p=0.6697$, for the interaction effect of group size and subjects' type, $F(1,80)=10.42, p=0.0018$, for the interaction effect of subjects' hometown and subjects' type, $F(3$, $80)=11.14, p=0.0000$, and for the interaction effect of all the three factors, $F(3,80)=26.13, p=$ 0.0000 .
} 
We ran the Wilcoxon rank sum test to investigate how group size, subjects' hometown, and subjects' type affect payoffs. The results are reported in Table 5. As shown in the table, the payoffs of type 1 are significantly different between the individual and team treatments in the Coast-Inland and Inland-Coast sessions but not in the Coast-Coast and Inland-Inland sessions. As for the subjects of type 2, we observe a significant effect of group size on the payoffs in all the sessions except for the Coast-Coast session:

RESULT 2a. When commodity exchanges were conducted among subjects from different areas, group size and subjects' type matter significantly in payoffs, however, this effect went into different directions according to where the subjects were from. When the subjects of type 1 were from coastal areas and the subjects of type 2 were from inland areas, increasing group size from one to two raised up the payoffs of type 1 and lowered the payoffs of type 2 . In contrast, when the subjects of type 1 were from inland areas and the subjects of type 2 were from coastal areas, increasing group size from one to two lowered the payoffs of type 1 and raised the payoffs of type 2 .

RESULT 2b. When commodity exchanges were conducted among subjects from the same areas, whether group size and subjects' type matter significantly in payoffs depended on where the subjects were from. When subjects of both types were from coastal areas, increasing group size from one to two did not matter significantly in the payoffs of both types. When subjects of both types were from inland areas, increasing group size from one to two significantly raised up the payoffs of type 2 but left the payoffs of type 1 unchanged.

$<$ Insert Table 5 here $>$

\subsection{Number of trades}

The average number of trades per period is presented in Figure 6. From the figure, we observe that (i) compared to the team treatment the subjects in the individual treatment seem to trade more frequently in all sessions; and (ii) the number of trades also seems to be different according to where subjects are from. These are confirmed by a two-way ANOVA. Although the interaction effect of group size and subjects' hometown is not significant $(F(3,32)=1.15, p$-value $=0.3429)$, the main effects of 
each factor are significant (for group size, $F(1,32)=10.23$, $p$-value $=0.0031$, and for subjects' hometown, $F(3,32)=2.73$, $p$-value $=0.0599)$.

\section{$<$ Insert Figure 6 here $>$}

In order to investigate how group size and subjects' hometowns affect the number of trades, we ran the Wilcoxon rank sum test through comparing the number of trades in the individual treatment with those in the team treatment. The test result indicates that the number of trades between the individual and team treatments is significantly different in the sessions where subjects are from different areas (i.e., the sessions of Coast-Inland and Inland-Coast) but not in the sessions where subjects are from the same areas (i.e., the sessions of Coast-Coast and Inland-Inland). ${ }^{11}$ More detailed results are presented as follows.

RESULT 3a. When commodity exchanges were conducted between subjects from different areas, increasing group size from one to two decreased the number of trades.

RESULT 3b. When commodity exchanges were conducted between subjects from the same areas, increasing group size from one to two did not have any significant effect on the number of trades.

\section{Discussion}

An important issue related to the trading ratio is worth noting that for the subjects of type 1 (resp. type 2) who have more endowment of $\mathrm{X}$ (resp. Y), a low trading ratio of $\mathrm{Y}$ to $\mathrm{X}$ stands for a weak (resp. strong) bargaining power while a high trading ratio of $\mathrm{Y}$ to $\mathrm{X}$ stands for a strong (resp. weak) bargaining power. Consequently, RESULTS 1a and $1 \mathrm{~b}$ implied that teamwork strengthened the bargaining power of subjects from coastal areas but weakened that of subjects from inland areas when commodity exchanges were conducted between subjects from different areas. Why did the effects of teamwork on the bargaining power of subjects from coastal and inland areas go into a different direction? Although not yet confirmed by field evidences, several possible explanations are conceivable.

11 For Coast-Coast, $z=1.167, p=0.2433$, for Inland-Inland, $z=0.318, p=0.7503$, for Coast-Inland, $z=1.956, p=0.0504$, and for Inland-Coast, $z=2.128, p=0.0333$. 
First, China's economic development started 15 years earlier in coastal areas than in inland areas. This conduces to a fact that compared to subjects from inland areas those from coastal areas are more economic-savvy and their thoughts are more westernized. Consequently, they are more familiar with teamwork processes than their counterparts from inland areas, and as a result, their bargaining power was enhanced. Second, traditional Chinese culture and society feature strong vertical relationships of filial piety, paternalism, and hierarchy. These vertical relationships would promote teamwork if teams are formed by managerial authority and have strong appointed leaders (i.e., a top-down control). However, the vertical relationships would demote the outcome of teamwork if there is no apparent team leader in the team. Our experiment is, indeed, a case of the latter since no one could easily become the leader in a team of two subjects that were just randomly matched. Therefore, in such a case communication and cooperation abilities of both team members are crucial to the success of any team effort. In China, compared to people from inland areas those from coastal areas are, in general, good at communicating and cooperating ${ }^{12}$, our results are consistent with these observations.

Regarding the results of subjects' payoffs, RESULTS 2a and $2 \mathrm{~b}$ are completely consistent with RESULTS 1a and 1b. As reflected from the payoff tables in Appendix 3, for the subjects of type 1 (resp. type 2), a low trading ratio of $Y$ to $X$ means that it costs them more $X$ (resp. less Y) in exchange of Y (resp. X), which consequently would lead to low (resp. high) payoffs of the subjects of type 1 (resp. type 2). Therefore, on the one hand, when the subjects of type 1 (resp. type 2) were from coastal areas and the subjects of type 2 (resp. type 1) were from inland areas, increasing group size from one to two raised up (resp. lowered) the trading ratios, and as a result the payoffs of type 1 (resp. type 2) increased and the payoffs of type 2 (resp. type 1) decreased. On the other hand, when subjects of both types were from coastal areas, increasing group size from one to two did not matter significantly in trading ratios, therefore, did not affect the payoffs of subjects of both types significantly. Again, when subjects of both types were from inland areas, increasing group size from one to two significantly lowered the trading ratios, as a result, the payoffs of type 2 increased and the payoffs of type 1 decreased.

The number of trades significantly differed between the individual and team

\footnotetext{
12 Although not served as a strongly supportive evidence, we observed that in the team treatment subjects from coastal areas communicated more actively with their partners than those from inland areas.
} 
treatments, however, only in the cases that commodity exchanges were conducted among subjects from different areas but not in the other cases that commodity exchanges were conducted among subjects from the same areas. Table 6 presents an alternative but related analysis. In the table, the average amounts of both commodities $\mathrm{X}$ and $\mathrm{Y}$ exchanged per trade in the individual and team treatments were separately calculated by whether subjects were from the same areas or from different areas. The table shows that there was almost no difference in the average amounts of commodities exchanged per trade between the individual and team treatments (13.3833 versus 14.1636) if subjects of both types were from the same areas. The average amounts of commodities per trade in the team treatment were about $28 \%$ more than those in the individual treatment (15.2647 versus 11.913) if subjects of both types were from different areas. ${ }^{13}$ Based on this related evidence, here, we provide an explanation that may help to interpret RESULTS 3a and 3b. Compared to when commodity exchanges were conducted among subjects from the same areas, subjects would be more cautious in trading with their counterparts who were from different areas, which consequently caused reduced number of commodities per trade. Meanwhile, the amount exchanged per trade was generally larger in the team treatment than in the individual treatment, because in the team treatment team members had chances to discuss together while in the individual treatment communication was possible only between trading partners. Based upon the above two considerations, the amount of commodities exchanged per trade was determined by a combined effect of these two factors. In our case, it seemed that when commodity exchanges were conducted among subjects from different areas, the effect of inter-subject discussion in teams overshadowed that of trading with the subjects from different areas. As a result, the amount of commodities exchanged per trade was significantly larger and consequently the number of trades was significantly smaller in the team treatment than in the individual treatment.

\section{$<$ Insert Table 6 here $>$}

Finally, we explain differences between our experimental results and several previous studies. For example, Kocher and Sutter (2005), Kocher et al. (2006) and Sutter (2005) offered supportive evidence for groups being more cognitively sophisticated than individuals. According to this context, in our experiment, the trading

13 The results of Wilcoxon rank sum test supported these results. $z=-0.744, p=0.4568$ in the case that subjects of both types were from the same areas and $z=-2.272, p=0.0231$ in the case that subjects of both types were from different areas, comparing the amounts exchanged per trade in the individual treatment to those in the team treatment. 
ratio of $\mathrm{Y}$ to $\mathrm{X}$ should reach one of the three equilibria more easily in the team treatment than in the individual treatment. However, this was not observed in our results except in the team Inland-Coast session where the trading ratio of $\mathrm{Y}$ to $\mathrm{X}$ converged to the low equilibrium. In addition, Kugler et al. (2007) provided evidence for supporting that groups may decrease welfare because of stronger self-interested preferences. This was partly observed in our results, however, opposite evidence was also observed. We found that group size affected payoffs in different directions according to where the subjects were from. This finding implies that it is important to take one's hometown into account when comparing economic behavior or decision-making between teams and individuals, especially in the countries or regions where hometown diversity plays a central role in explaining differences in business management and local market performance.

\section{Conclusion}

We have examined whether there are potential differences between team and individual trades and whether there are potential effects of subjects' hometowns on their trading behaviors in an experimental market. To the best of our knowledge, our experiment is the first to document these group-size and hometown effects in China. We found that teamwork strengthened the bargaining power of subjects from coastal areas but weakened that of subjects from inland areas when commodity exchanges were conducted between subjects from different areas.

We observed that when the subjects of both types were from inland areas, increasing group size from one to two significantly lowered the trading ratios (see RESULT 1b). A possible explanation is that since the hometowns of our subjects were simply categorized into two areas (i.e., coastal and inland areas) and the number of hometowns in inland areas categorized by provinces (i.e., 19) was about twice as large as that in coastal areas (i.e., 9), hence, there may exist heterogeneous characters even in the subjects from inland areas. Our experimental data may not have offered a precise test on the above explanation. We leave this issue as a future task by providing more sophisticated categorization of subjects' hometowns.

\section{References}

Bornstein G., and Yaniv I., 1998. Individual and group behaviour in the ultimatum game: are groups more "rational” players?. Experimental Economics, 1, 101-108. 
Cason T. N., and Mui V., 1997. A laboratory study of group polarization in the team dictator game. Economic Journal, 107, 1465-1483.

Charness G., and Sutter M., 2012. Groups make better self-interested decisions. Journal of Economic Perspectives, 26(3), 157-176.

Cooper D. J., and Kagel J. H., 2005. Are two heads better than one? Team versus individual play in signaling games. American Economic Review, 95(3), 477-509.

Crockett S., Oprea R., and Plott C., 2011. Extreme Walrasian dynamics: the Gale example in the lab. American Economic Review, 101(7), 3196-3220.

Gale D., 1963. A note on global instability of competitive equilibrium. Naval Research Logistics Quarterly, 10, 81-87.

Huber J., Shubik M., and Sunder S., 2009. Default penalty as a disciplinary and selection mechanism in presence of multiple equilibria. Cowles Foundation Discussion Paper No. 1730, Yale University.

Kocher M. G., and Sutter M., 2005. The decision maker matters: Individual versus group behavior in experimental beauty-contest games. Economic Journal, 115, 200-223.

Kocher M. G., Strauß S., and Sutter M., 2006. Individual or team decision making Cause and consequences of self-selection. Games and Economic Behavior, 56(2), 259-270.

Kugler T., Bornstein G., Kocher M. G., and Sutter M., 2007. Trust between individuals and groups: Groups are less trusting than individuals but just as trustworthy. Journal of Economic Psychology, 28(6), 646-657.

Shapley L. S., and Shubik M., 1977. An example of a trading economy with three competitive equilibria. Journal of Political Economy, 85, 873-875.

Sutter M., 2005. Are four heads better than two? An experimental beauty-contest game with teams of different size. Economic Letters, 88(1), 41-46. 
Tsang E. W. K., 1998. Can guanxi be a source of sustained competitive advantage for doing business in China?. The Academy of Management Executive, 12(2), 64-73.

Zhang K. H., 2001. What attracts foreign multinational corporations to China?. Contemporary Economic Policy, 19(3), 336-346. 


\section{Appendix 1. Formal Definitions of Concepts in an Exchange Economy Model}

First of all, we give formal definitions of "two-good exchange economy," "budget correspondence" and "individual demand function":

DEFINITION 1. A two-good exchange economy is a list $(I, U, \omega)$ such that $I$ is a nonempty finite set, $U=\left(U_{i}\right)_{i \in I}$ is a profile of real-valued functions defined over $\mathrm{R}_{+}^{2}$, and $\omega=\left(\omega_{i}\right)_{i \in I}$, where $\omega_{i}=\left(\bar{x}_{i}, \bar{y}_{i}\right)$, is a profile of points of $\mathrm{R}_{+}^{2}$. Each element of $I$ is called a consumer. For each $i \in I, U_{i}$ and $\omega_{i}$ are called the utility function, and the individual endowment, of consumer $i$, respectively.

DEFINITION 2. Let $(I, U, \omega)$ be a two-good exchange economy. The budget correspondence $B_{i}$ and the individual demand function $d_{i}$ of consumer $i$ are defined by

$$
\begin{aligned}
& B_{i}\left(p_{X}, p_{Y}\right)=\left\{\left(x_{i}, y_{i}\right) \in \mathrm{R}_{+}^{2} \mid p_{X} x_{i}+p_{Y} y_{i} \leq p_{X} \overline{x_{i}}+p_{Y} \overline{y_{i}}\right\} ; \text { and } \\
& d_{i}\left(p_{X}, p_{Y}\right)=\left\{\left(x_{i}, y_{i}\right) \in B_{i}\left(p_{X}, p_{Y}\right) \mid U_{i}\left(x_{i}, y_{i}\right) \geq U_{i}\left(x_{i}^{\prime}, y_{i}^{\prime}\right) \text { for each }\left(x_{i}^{\prime}, y_{i}^{\prime}\right) \in\right. \\
& \left.B_{i}\left(p_{X}, p_{Y}\right)\right\}
\end{aligned}
$$

for each $\left(p_{X}, p_{Y}\right) \in \mathrm{R}_{++}^{2}$. For each consumer $i$, define the functions $d_{X i}$ and $d_{Y i}$ by $d_{i}\left(p_{X}, p_{Y}\right)=\left(d_{X i}\left(p_{X}, p_{Y}\right), d_{Y i}\left(p_{X}, p_{Y}\right)\right)$ for each $\left(p_{X}, p_{Y}\right) \in \mathrm{R}_{++}^{2}$, then $d_{X i}$ and $d_{Y i}$ are respectively called the individual demand functions for $X$ and $Y$ of consumer $i$.

Notice that the budget correspondence and the individual demand function of a consumer are zero-homogeneous. It means that their intrinsic valuable is the ratio of $p_{X}$ to $p_{Y}$, namely $B_{i}\left(p_{X}, p_{Y}\right)=B_{i}\left(p_{X} / p_{Y}, 1\right)$ and $d_{i}\left(p_{X}, p_{Y}\right)=d_{i}\left(p_{X} / p_{Y}, 1\right)$. To make our analysis simpler, we consider the relative price $p=p_{X} / p_{Y}$ as an independent valuable. We are now ready to define the classical market equilibrium concept for prediction. 
DEFINITION 3. Let $(I, U, \omega)$ be a two-good exchange economy. The profile of non-negative vectors $\left(x_{i}, y_{i}\right)_{i \in I}$ is called an allocation of $(I, U, \omega)$ if $\sum_{i \in I} x_{i}=\sum_{i \in I} \overline{x_{i}}$ and $\sum_{i \in I} y_{i}=\sum_{i \in I} \overline{y_{i}}$. The vector $\left(\left(x_{i}{ }^{*}, y_{i}{ }^{*}\right)_{i \in I}, p^{*}\right) \in\left(\mathrm{R}_{+}^{2}\right)^{I} \times \mathrm{R}$ is a competitive equilibrium, or simply equilibrium, for $(I, U, \omega)$ if $\left(x_{i}^{*}, y_{i}^{*}\right)=d_{i}\left(p^{*}, 1\right)$ for each $i \in I$; and $\left(x_{i}^{*}, y_{i}^{*}\right)_{i \in I}$ is an allocation of $(I, U, \omega)$. The allocation $\left(x_{i}^{*}, y_{i}^{*}\right)_{i \in I}$, and the real number $p^{*}$ are called an equilibrium allocation, and an equilibrium price, for $(I, U, \omega)$, respectively.

DEFINITION 4. Let $(I, U, \omega)$ be a two-good exchange economy. For each $p>0$, we define the set of the demanders $I D(p)$ for $X$ and the set of the suppliers $I S(p)$ of $X$ by

$$
\begin{aligned}
& I D(p)=\left\{i \in I \mid d_{X i}(p, 1)-\bar{x}_{i} \geq 0\right\} ; \text { and } \\
& I S(p)=\left\{i \in I \mid d_{X i}(p, 1)-\bar{x}_{i}<0\right\} .
\end{aligned}
$$

The market demand function, simply demand function for $X$, is defined by

$$
D_{X}(p)=\sum_{i \in I D(p)}\left[d_{X i}(p, 1)-\bar{x}_{i}\right],
$$

the market supply function, simply supply function of $X$, is defined by

$$
S_{X}(p)=\sum_{i \in I S(p)}\left[\bar{X}_{i}-d_{X i}(p, 1)\right],
$$

and the market excess demand function, simply excess demand function for $X$, is defined by

$$
E_{X}(p)=\sum_{i \in I}\left[d_{X i}(p, 1)-\bar{x}_{i}\right]
$$

for each $p>0$.

Notice that $E_{X}(p)=D_{X}(p)-S_{X}(p)$, and $p^{*}$ is an equilibrium price if and only if $E_{X}\left(p^{*}\right)=0$. Then, by using the excess demand function, we define the following classical concepts to describe whether an equilibrium is likely to be attained or not:

DEFINITION 5. Let $E_{X}$ be the excess demand function for $X$ in the two-good 
economy $(I, U, \omega)$. Then Walrasian adjustment process with the excess demand function $E_{X}$ is the ordinary differential equation: $\dot{p}=W\left(E_{X}(p)\right)^{14}$, where $W$ is a real-valued function defined over R such that $W(0)=0$ and $W^{\prime}(z)>0$ for each $z \in$ R. Suppose that $E_{X}\left(p^{*}\right)=0$. We say that $p^{*}$ is locally stable (resp. locally unstable) if $E_{X}^{\prime}\left(p^{*}\right)<0$ (resp. $\left.E_{X}^{\prime}\left(p^{*}\right)>0\right)$. The competitive equilibrium $\left(\left(x_{i}^{*}, y_{i}^{*}\right)_{i \in I},\left(p^{*}, 1\right)\right)$ is called a locally stable equilibrium (resp. locally unstable equilibrium) if $p^{*}$ is locally stable (resp. locally unstable) .

${ }^{14}$ The notation $\dot{p}$ indicates the derivative of $p$ with respect to time. 


\section{Appendix 2. Experimental Instruction}

This is an experiment about decision making and economics. The instructions are simple. If you follow them carefully and make good decisions, you might earn a considerable amount of money that will be paid to you. In this experiment, you will make decisions to trade or hold two kinds of commodities, called $\mathrm{X}$ and $\mathrm{Y}$ in a sequence of trading periods.

\section{Introduction}

1. There are ( 12 ) trading teams in total, and each team has one/two participants. ${ }^{15}$ Please make sure that you have the following items:
a) "Payoff Table” (one)
b) "Record Sheet” (three)
c) Name tag (one)

2. Please check whether your team name (A, B, C...) in your "Record Sheet" is the same as the first letter in your name tag.

3. The "Payoff Table" of your team is your own SECRET information. You are NOT allowed to reveal the information regarding your "Payoff Table" to any other team. We will show you how to read the "Payoff Table" later.

4. At the beginning of each period of the experiment, your team will be given some amounts of Commodity X and/or Y. These amounts are shown in the first row of your "Record Sheet". This endowment is also your own SECRET information, so you are NOT allowed to reveal the information regarding your endowment to any other team.

\section{Trading Rules}

The trading rules are as follows:

1. First of all, please put on your team name tag so that the other teams can see your team name.

\footnotetext{
${ }^{15}$ Here, "each team has one participant" refers to the individual treatment, and "each team has two participants" refers to the team treatment.
} 
2. Each team will be given pink cards and/or white cards in an envelope. One pink card is one unit of commodity X, and one white card is one unit of commodity Y. The number of pink cards (resp., white cards) equals to the amount of Commodity $\mathrm{X}$ (resp., Commodity Y) in the first row of your "Record Sheet." You can take pink and white cards (Commodities $\mathrm{X}$ and $\mathrm{Y}$ ) out of the envelope only when you check the number of cards or trade them.

3. Walk around this room and find a team to trade. Be careful NOT to reveal to any other team the "Payoff Table" and the "Record Sheet" of your team. The same notice applies to the following steps 4,5 , and 6 .

4. Start a negotiation when you find a team that wants to trade with you. You CANNOT give Commodity $\mathrm{X}$ or $\mathrm{Y}$ more than you hold to the team. Moreover, the trading ratio of $\mathrm{Y}$ to $\mathrm{X}(=($ Amount of $\mathrm{Y}) /($ Amount of $\mathrm{X}))$ should be greater than or equal to $(1 / 4=0.25 \quad)$. Remember that the trading ratio of $\mathrm{Y}$ to $\mathrm{X}$ cannot be less than $(1 / 4=0.25 \quad)$.

5. If you reach an agreement, then report the agreement to an experimenter. In front of the experimenter, trade Commodity $\mathrm{X}$ with Commodity $\mathrm{Y}$ according to the agreement. After that, write the trading result in your "Record Sheet." This is the end of one trade.

6. Repeat the above steps 3-5 after one trade is completed. You have ( 10$)$ minutes for each period. You can trade as many times as you want within the time limit. For the next team to trade with, you can choose any team: it may be the same as or different from one of the teams you have already traded. We accept only agreements that have reached within the time limit.

7. Please go back to your seat after each period. Please make sure that all commodity cards you traded are in your envelope. This is the end of the first period.

8. At the beginning of the second period, you will receive the same materials as those of the first period. That is, the amounts of Commodities $\mathrm{X}$ and $\mathrm{Y}$ you initially have at Period 2 are the same as those at the beginning of Period 1. We will distribute pink cards and /or white cards in an envelope. Those amounts are shown in your "Record Sheet”. We will also collect the commodity cards and the envelope used in Period 1. After a 2-minute break, Period 2 starts. This experiment has 5 periods. The above steps 
are repeated 5 times.

\section{An Example}

We will give you an example to explain how to read the "Payoff Table" and how to fill out the "Record Sheet" by way of an example. In the following explanations, we will use the "Pilot Payoff Table" which has nothing to do with the "Payoff Table," but the "Pilot Payoff Table" should help you read the "Payoff Table" in the experiment.

1. Suppose that your team name is "A".

2. Take a look at Table 1-(a). The endowment of your team is shown in the second row of the "Record Sheet." In this example, your team is given endowment of 9 units of Commodity X and 8 units of Commodity Y.

\section{Record Sheet}

Date (day/month/year):

Time:

\begin{tabular}{llll}
\hline Team Name: $\mathbf{A}$ & & & \\
\hline Your Name Tag ID: & $\mathbf{x x x x x} \quad$ Your Name $\quad \mathbf{x x x x x} \quad \mathbf{x x x x x}$ \\
\hline
\end{tabular}

\section{Period 1}

\begin{tabular}{|r|c|c|c|c|c|c|}
\hline $\begin{array}{l}\text { Trade } \\
\text { Number }\end{array}$ & $\begin{array}{c}\text { Amount of } \\
\text { Change in X }\end{array}$ & $\begin{array}{c}\text { Amount of } \\
\text { Change in Y }\end{array}$ & $\begin{array}{c}\text { Team You } \\
\text { Trade with }\end{array}$ & $\begin{array}{c}\text { Amount of } \\
\text { X }\end{array}$ & $\begin{array}{c}\text { Amount of } \\
\text { Y }\end{array}$ & Payoff \\
\hline 0 & & & & $\mathbf{9}$ & $\mathbf{8}$ & $\mathbf{4 9 0 5}$ \\
\hline 1 & & & & & & \\
\hline
\end{tabular}

Table 1-(a)

Next please see Table 2. This table represents a part of the "Pilot Payoff Table." In this table, the horizontally aligned numbers denote the amounts of Commodity $\mathrm{X}$ and the vertically aligned numbers denotes the amounts of Commodity Y. Your team is endowed with 9 units of Commodity X and 8 units of Commodity Y, so the initial payoff of your team is the number in the cell of column 9 - row 8 , that is, 4905 . This number is the value shown in the "Payoff" of "Trade Number 0" in the "Record Sheet". 


\begin{tabular}{|r|r|r|r|r|r|r|r|r|r|l|}
\hline \multicolumn{10}{|c|}{ Pilot Payoff Table } \\
\hline 25 & $\cdots$ & 7209 & 7284 & 7359 & 7434 & 7509 & 7584 & 7659 & 7734 & $\cdots$ \\
\hline 24 & $\cdots$ & 7145 & 7220 & 7295 & 7370 & 7445 & 7520 & 7595 & 7670 & $\cdots$ \\
\hline 23 & $\cdots$ & 7073 & 7148 & 7223 & 7298 & 7373 & 7448 & 7523 & 7598 & $\cdots$ \\
\hline 22 & $\cdots$ & 6994 & 7069 & 7144 & 7219 & 7294 & 7369 & 7444 & 7519 & $\cdots$ \\
\hline 21 & $\cdots$ & 6907 & 6982 & 7057 & 7132 & 7207 & 7282 & 7357 & 7432 & $\cdots$ \\
\hline 20 & $\cdots$ & 6810 & 6885 & 6960 & 7035 & 7110 & 7185 & 7260 & 7335 & $\cdots$ \\
\hline 19 & $\cdots$ & 6703 & 6778 & 6853 & 6928 & 7003 & 7078 & 7153 & 7228 & $\cdots$ \\
\hline 18 & $\cdots$ & 6585 & 6660 & 6735 & 6810 & 6885 & 6960 & 7035 & 7110 & $\cdots$ \\
\hline 17 & $\cdots$ & 6455 & 6530 & 6605 & 6680 & 6755 & 6830 & 6905 & 6980 & $\cdots$ \\
\hline 16 & $\cdots$ & 6311 & 6386 & 6461 & 6536 & 6611 & 6686 & 6761 & 6836 & $\cdots$ \\
\hline 15 & $\cdots$ & 6152 & 6227 & 6302 & 6377 & 6452 & 6527 & 6602 & 6677 & $\cdots$ \\
\hline 14 & $\cdots$ & 5976 & 6051 & 6126 & 6201 & 6276 & 6351 & 6426 & 6501 & $\cdots$ \\
\hline 13 & $\cdots$ & 5781 & 5856 & 5931 & 6086 & 6081 & 6156 & 6231 & 6306 & $\cdots$ \\
\hline 12 & $\cdots$ & 5566 & 5641 & 5716 & 5791 & 5866 & 5941 & 6016 & 6091 & $\cdots$ \\
\hline 11 & $\cdots$ & 5328 & 5403 & 5478 & 5553 & 5628 & 5703 & 5778 & 5853 & $\cdots$ \\
\hline 10 & $\cdots$ & 5066 & 5141 & 5216 & 5291 & 5366 & 5441 & 5516 & 5591 & $\cdots$ \\
\hline 9 & $\cdots$ & 4776 & 4851 & 4926 & 5001 & 5076 & 5151 & 5226 & 5301 & $\cdots$ \\
\hline 8 & $\cdots$ & 4455 & 4530 & 4605 & 4680 & 4755 & 4830 & 4905 & 4980 & $\cdots$ \\
\hline 7 & $\cdots$ & 4101 & 4176 & 4251 & 4326 & 4401 & 4476 & 4551 & 4626 & $\cdots$ \\
\hline 6 & $\cdots$ & 3709 & 3784 & 3859 & 3934 & 4009 & 4084 & 4159 & 4234 & $\cdots$ \\
\hline 5 & $\cdots$ & 3276 & 3351 & 3426 & 3501 & 3576 & 3651 & 3726 & 3801 & $\cdots$ \\
\hline 4 & $\cdots$ & 2798 & 2873 & 2948 & 3023 & 3098 & 3173 & 3248 & 3323 & $\cdots$ \\
\hline 3 & $\cdots$ & 2269 & 2344 & 2419 & 2494 & 2569 & 2644 & 2719 & 2794 & $\cdots$ \\
\hline 2 & $\cdots$ & 1685 & 1760 & 1835 & 1910 & 1985 & 2060 & 2135 & 2210 & $\cdots$ \\
\hline 1 & $\cdots$ & 1039 & 1114 & 1189 & 1264 & 1339 & 1414 & 1489 & 1564 & $\cdots$ \\
\hline 0 & $\cdots$ & 325 & 400 & 475 & 550 & 625 & 700 & 775 & 850 & $\cdots$ \\
\hline & $\cdots$ & 3 & 4 & 5 & 6 & 7 & 8 & 9 & 10 & $\cdots$ \\
\hline
\end{tabular}

Amount of $X$

Table 2

Let us begin the first trading.

3. Suppose that you negotiate with Team $B$, and the two teams reach the agreement that " 4 units of Commodity $\mathrm{X}$ that your team has are traded for 7 units of Commodity $\mathrm{Y}$ that Team B has."

4. Report the agreement to the experimenter. The experimenter will fill out the following table on the blackboard for you. 


\begin{tabular}{|c|c|c|c|c|}
\hline \multicolumn{5}{|c|}{ Deal } \\
\hline $\begin{array}{c}\text { Team that } \\
\text { gave } X\end{array}$ & $\begin{array}{c}\text { Amount } \\
\text { of } X\end{array}$ & $\begin{array}{c}\text { Team that } \\
\text { gave } Y\end{array}$ & $\begin{array}{c}\text { Amount } \\
\text { of } Y\end{array}$ & Ratio(=Y/X) \\
\hline A & 4 & B & 7 & 1.75 \\
\hline
\end{tabular}

Table 3-(a)

In this case, as shown in Table 3-(a), the experimenter writes " $A$ " in the blank of "Team that gave $X$ ”, “4” in "Amount of $X$ ”, “B” in "Team that gave $Y$ ” and "7” in "Amount of $\mathrm{Y}$.” Remember that the trading ratio of $\mathrm{Y}$ to $\mathrm{X}(=\mathrm{Y} / \mathrm{X})$ should be greater than or equal to $(1 / 4=0.25)$.

5. Following the experimenter's guidance, trade Commodity $\mathrm{X}$ for $\mathrm{Y}$ according to the agreement. Your team gives 4 pink cards (Commodity $\mathrm{X}$ ) to Team B and instead receives 7 white cards (Commodity Y) from Team B.

6. Next please fill out your "Record Sheet." See Table 1-(b). Write "-4" in the blank of "Amount of Change in X", "7" in "Amount of Change in Y", and "B" in "Team You Trade with" in the second row of "Trade Number 1 ” of the "Record Sheet".

As a result of this trade, your team now holds 5 units of Commodity $\mathrm{X}$ and 15 units of Commodity Y. According to the "Pilot Payoff Table" (Table 2), you will find that the payoff of your team is “6302.”

Write " 5 ” in the blank of “Amount of X," “15” in "Amount of Y," and “6302” in "Payoff". 


\section{Record Sheet}

Date (day/month/year):

Time:

\begin{tabular}{|c|c|c|c|c|}
\hline Team Name: & & & & \\
\hline Your Name Tag ID: & $\mathbf{x x x x x}$ & Your Name & $\mathbf{x x x x x}$ & $\operatorname{xxxxx}$ \\
\hline
\end{tabular}

Period 1

\begin{tabular}{|r|c|c|c|c|c|c|}
\hline $\begin{array}{l}\text { Trade } \\
\text { Number }\end{array}$ & $\begin{array}{c}\text { Amount of } \\
\text { Change in X }\end{array}$ & $\begin{array}{c}\text { Amount of } \\
\text { Change in Y }\end{array}$ & $\begin{array}{c}\text { Team You } \\
\text { Trade with }\end{array}$ & $\begin{array}{c}\text { Amount of } \\
X\end{array}$ & $\begin{array}{c}\text { Amount of } \\
Y\end{array}$ & Payoff \\
\hline 0 & & & & $\mathbf{9}$ & $\mathbf{8}$ & $\mathbf{4 9 0 5}$ \\
\hline 1 & $\mathbf{- 4}$ & $\mathbf{7}$ & $\mathbf{B}$ & $\mathbf{5}$ & $\mathbf{1 5}$ & $\mathbf{6 3 0 2}$ \\
\hline 2 & & & & & & \\
\hline
\end{tabular}

Table 1-(b)

Then, the first trading is completed. Now, let us move on to the second trading.

7. Suppose that you negotiate with Team $\mathrm{K}$ and agree "to trade your 2 units of commodity Y for Team K's 3 units of commodity X.”

8. Report the agreement to the experimenter. The experimenter will fill out the following table on the blackboard for you.

\begin{tabular}{|c|c|c|c|c|}
\hline \multicolumn{5}{|c|}{ Deal } \\
\hline $\begin{array}{c}\text { Team that } \\
\text { gave X }\end{array}$ & $\begin{array}{c}\text { Amount } \\
\text { of } \mathrm{T}\end{array}$ & $\begin{array}{c}\text { Team that } \\
\text { gave } \mathrm{Y}\end{array}$ & $\begin{array}{c}\text { Amount } \\
\text { of } \mathrm{Y}\end{array}$ & Ratio(=Y/X) \\
\hline A & 4 & B & 7 & 1.75 \\
\hline G & 5 & H & 4 & 0.8 \\
\hline L & 12 & F & 14 & 1.17 \\
\hline K & 3 & A & 2 & 0.67 \\
\hline & & & & \\
\hline
\end{tabular}

Table 3-(b)

As shown in Table 3-(b), the experimenter writes "K" in the blank of "Team that gave 
X”, "3” in "Amount of X," "A" in "Team that gave Y" and "2” in "Amount of Y."

9. Following the experimenter's guidance, trade commodities according to the agreement. You will give 2 white cards (commodity Y) to Team K, and in turn take 3 pink cards (commodity X).

10. Then, fill out your "Record Sheet" as follows. Look at the row of Trade 2 of Table 1-(c). Write "3" in the blank of "Amount of Change in X," "-2" in "Amount of Change in Y" and " $\mathrm{K}$ " in "Team You Trade with."

As a result of this trading, your team owns 8 units of $\mathrm{X}$ and 13 units of $\mathrm{Y}$. According to the "Pilot Payoff Table," your team's payoff is found to be 6156. So write " 8 " in the blank of "Amount of X," "13" in "Amount of Y" and "6156" in "Payoff."

\section{Record Sheet}

Date (day/month/year):

Time:

\begin{tabular}{lllll}
\hline Team Name: $\quad \mathbf{A}$ & & & & \\
\hline Your Name Tag ID: & $\mathbf{x x x x x}$ & Your Name & $\mathbf{x x x x x}$ & $\mathbf{x x x x x}$ \\
\hline
\end{tabular}

\section{Period 1}

\begin{tabular}{|r|c|c|c|c|c|c|}
\hline $\begin{array}{l}\text { Trade } \\
\text { Number }\end{array}$ & $\begin{array}{c}\text { Amount of } \\
\text { Change in X }\end{array}$ & $\begin{array}{c}\text { Amount of } \\
\text { Change in Y }\end{array}$ & $\begin{array}{c}\text { Team You } \\
\text { Trade with }\end{array}$ & $\begin{array}{c}\text { Amount of } \\
X\end{array}$ & $\begin{array}{c}\text { Amount of } \\
\text { Y }\end{array}$ & Payoff \\
\hline 0 & & & & 9 & $\mathbf{8}$ & $\mathbf{4 9 0 5}$ \\
\hline 1 & -4 & 7 & B & 5 & $\mathbf{1 5}$ & 6302 \\
\hline 2 & 3 & -2 & K & $\mathbf{8}$ & $\mathbf{1 3}$ & $\mathbf{6 1 5 6}$ \\
\hline
\end{tabular}

Table 1-(c)

Then, the second trading is completed.

Arrows in the "Pilot Payoff Table" indicate the changes in your payoff. In our experiment, you can make as many trades as you want within 10 minutes. 
Now we will explain about your earnings. Your earnings depend on the final payoff that your team earns in one randomly selected period from the experiment. This period is chosen by a random device after the experiment, so nobody can tell during the experiment. Your earnings are computed in the following way:

Your earnings $=$

(the final payoff of your team at one period randomly chosen $) \times\left(\begin{array}{ll}0.07\end{array}\right)$ $\mathrm{RMB}$

For example, suppose that (i) Period 1 is randomly selected after the experiment, and (ii) your final payoff at the end of Period 1 is ( $4156 \quad$ ) as in Table 1-(c). Then your

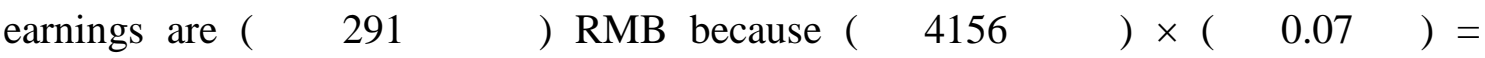
( 291$)$.

We round off the decimal places. Each member of the same team receives the same earnings.

That's all. If you have any questions, please raise your hand.

Now, let us start the experiment. First, look at the "Payoff Table." We will give you 5 minutes so that you can look over the table and understand it very well. During this period, please make sure that you completely understand all the rules.

If you have any questions, please let us know quietly. Our staff will come to help you. Please remember that you are NOT allowed to communicate with any other team until the experiment starts.

Meantime, our staff will distribute pink and/or white cards in an envelope. Notice that the trading period number is printed in each card. You can only use cards with the same number as the numbers of the period going on. For example, in Period 3, you can only use cards with “3”.

Remember that you are NOT allowed to reveal the information regarding your "Payoff Table" or the information regarding your "Record Sheet" to any other team. If this happens, the experiment will be stopped at that point. 


\section{Appendix 3. Payoff Tables}

\section{A. Payoff table for the type 1 subjects}

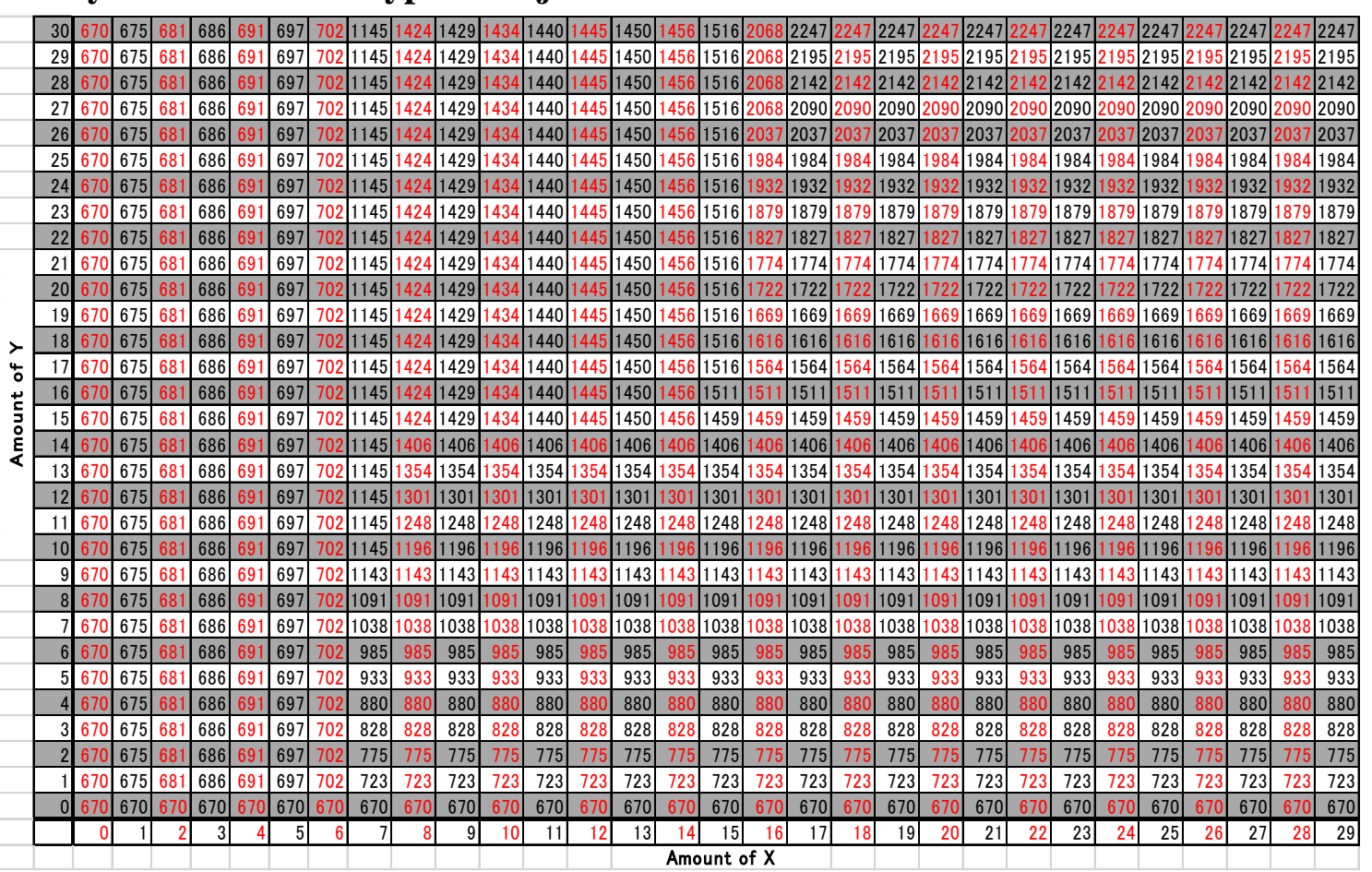

\section{B. Payoff table for the type $\mathbf{2}$ subjects}

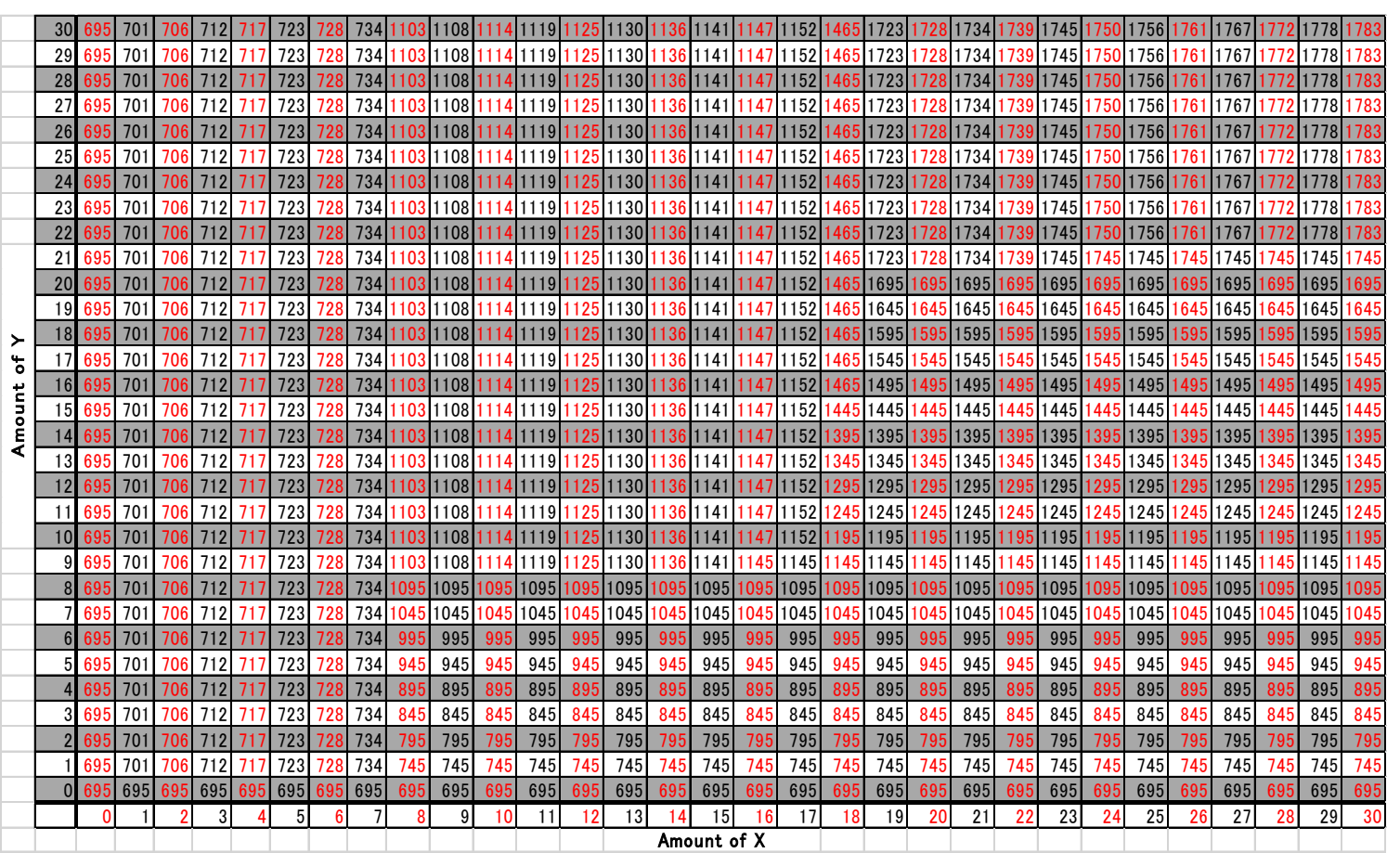




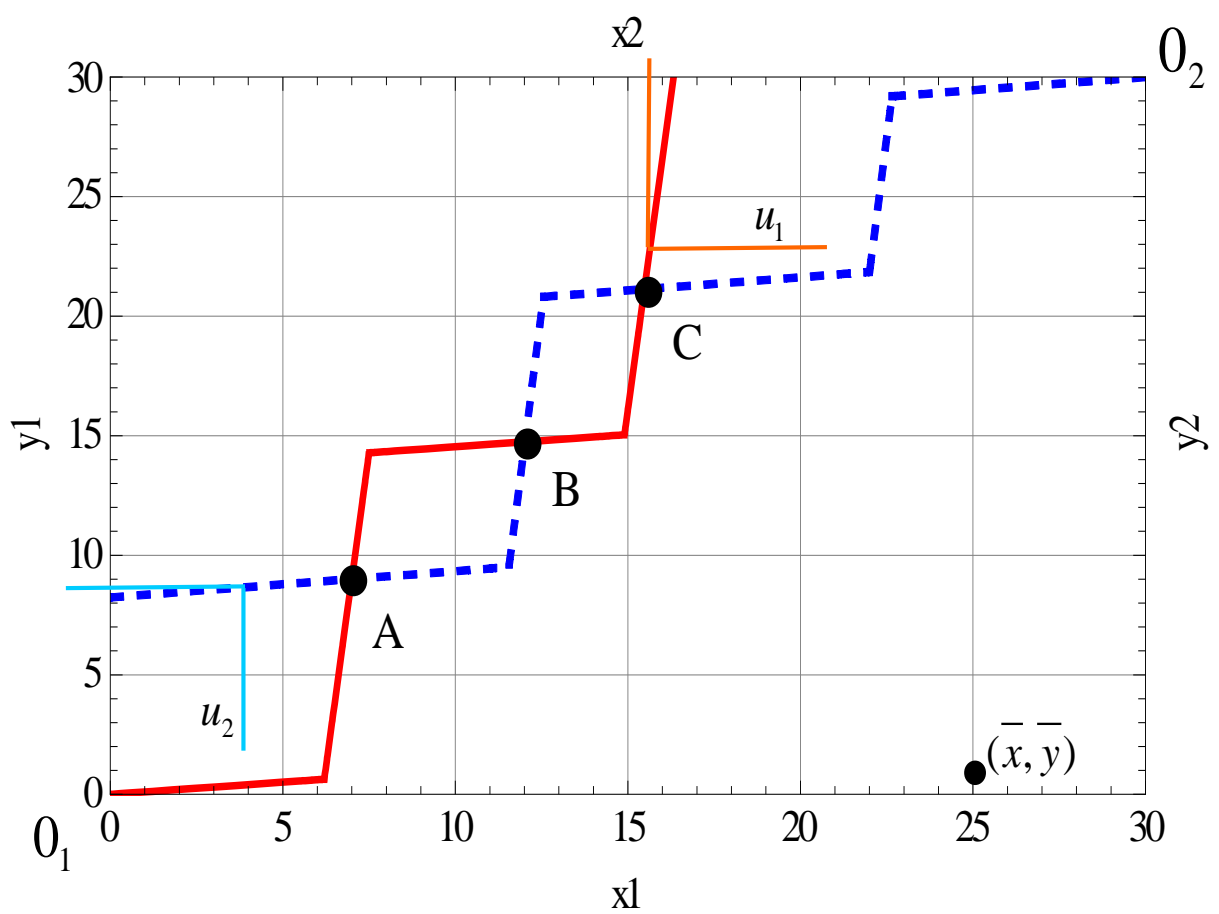

Figure 1. Exchange Economy with Three Competitive Equilibria

Excess Denand For $\mathrm{X}=E_{X}$

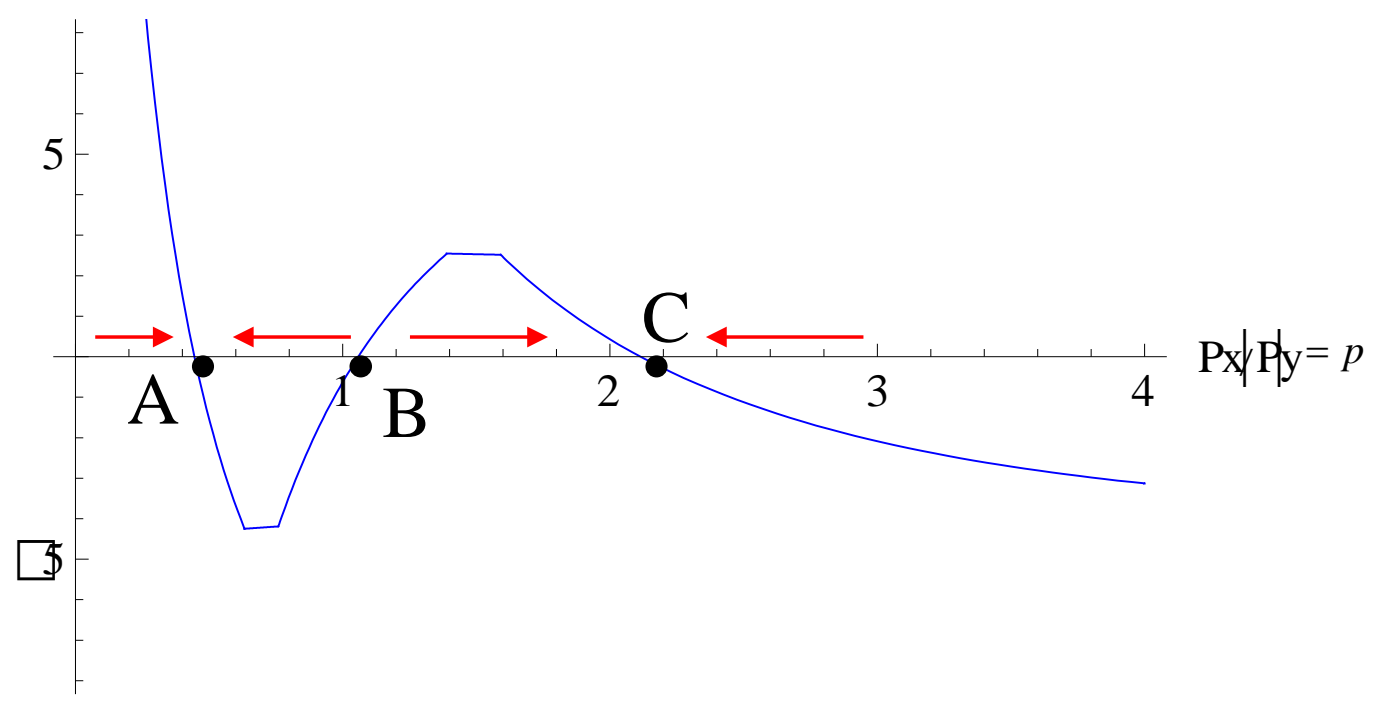

Figure 2. Excess Demand Function for $X$. 


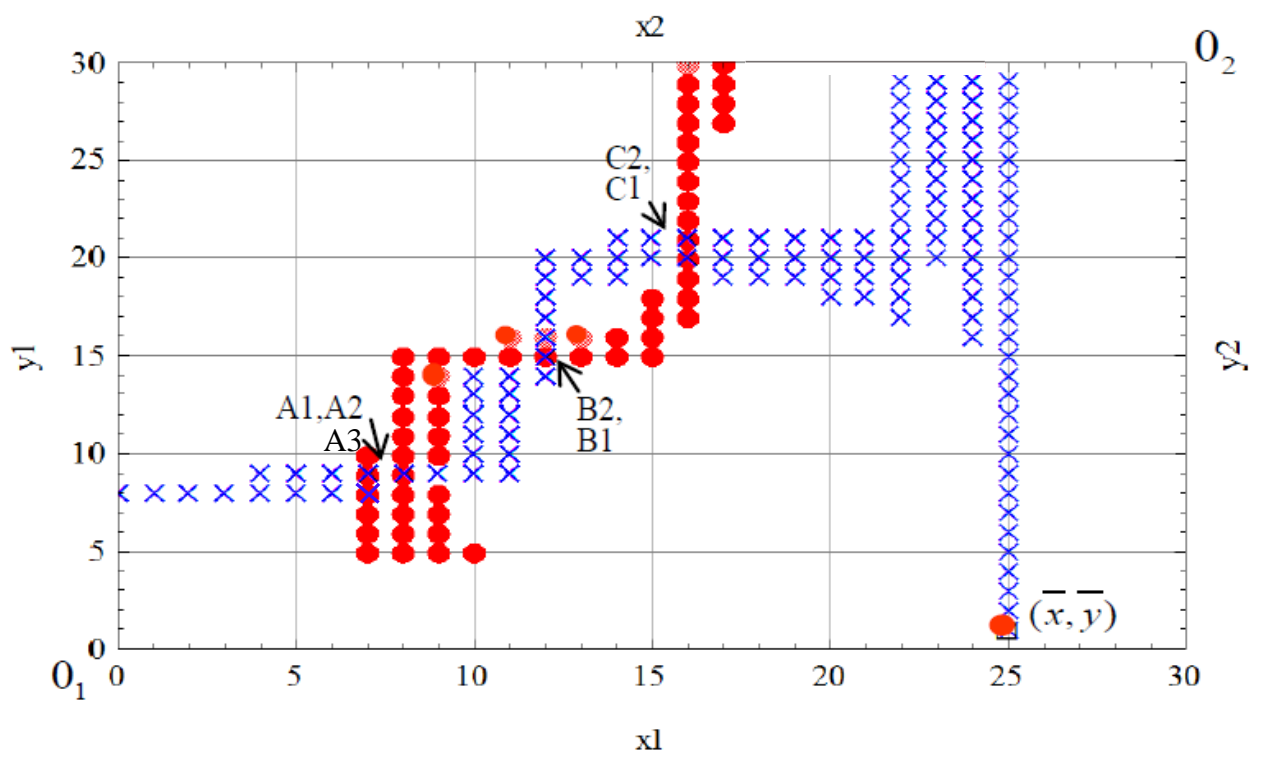

Figure 3. Discrete Version of the Exchange Economy 
Coast1-Coast1

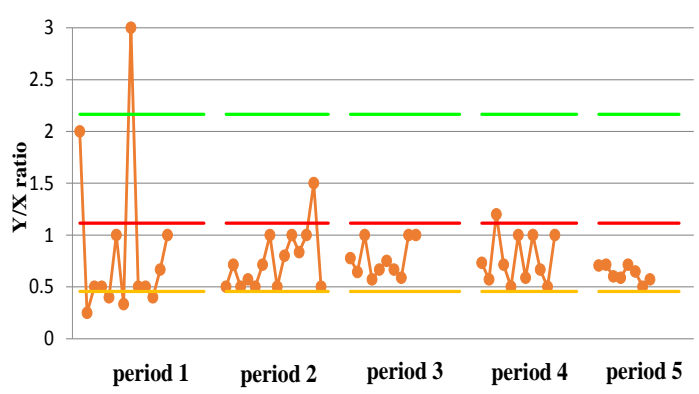

Coast1-Inland1

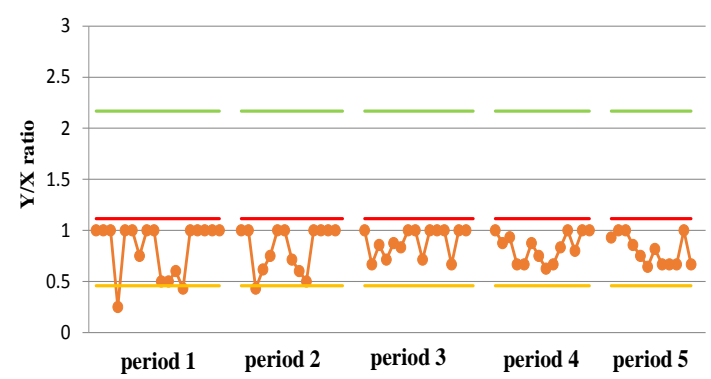

Coast2-Coast2

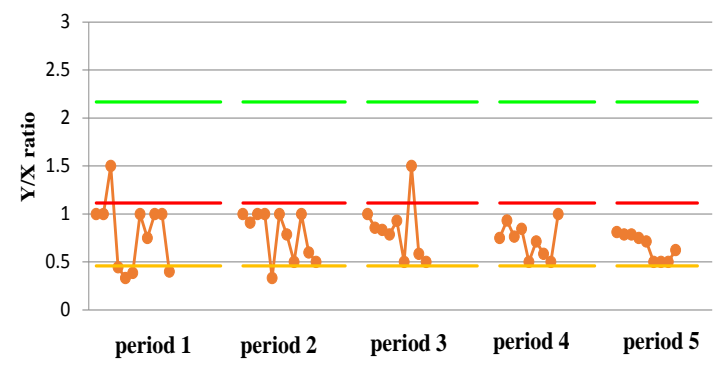

Coast2-Inland2

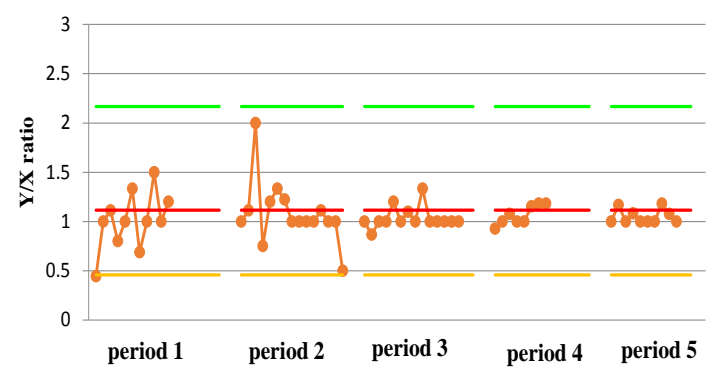

Inland1-Inland1

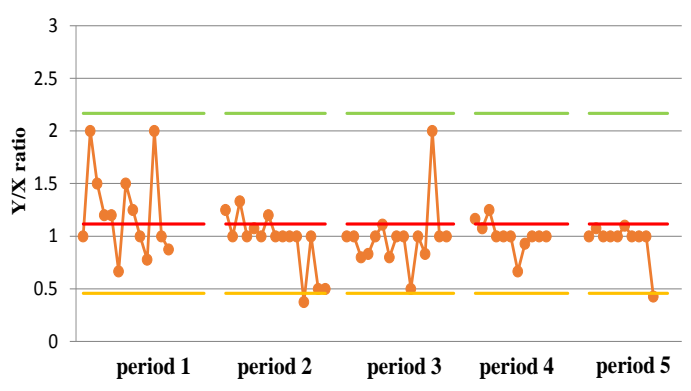

Inland1-Coast1

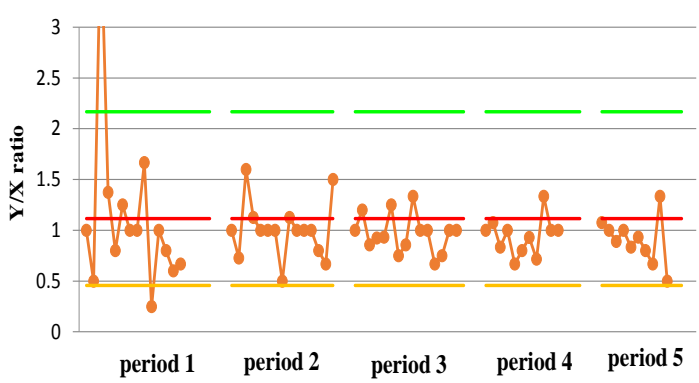

Inland2-Inland2

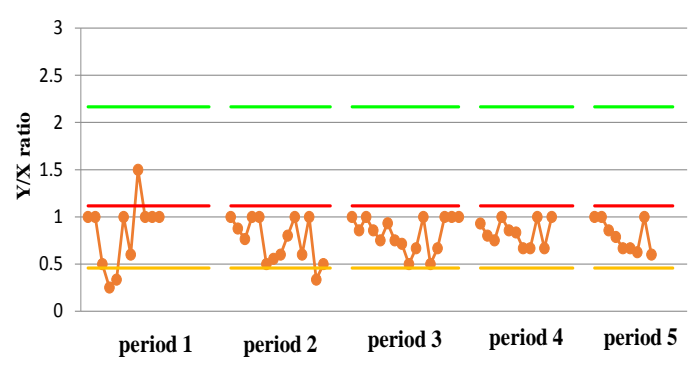

Inland2-Coast2

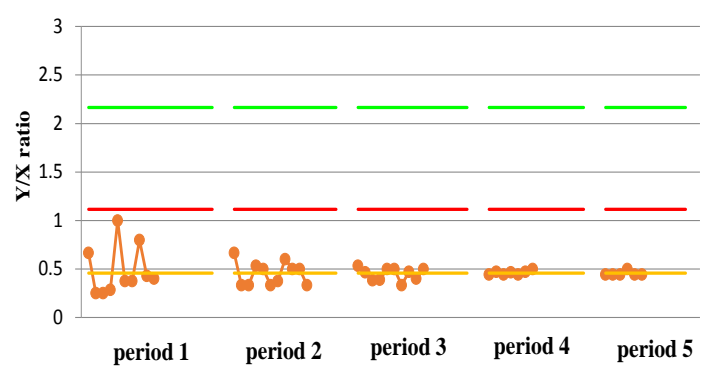

Figure 4. Trading ratio of $Y$ to $X$ in each session 


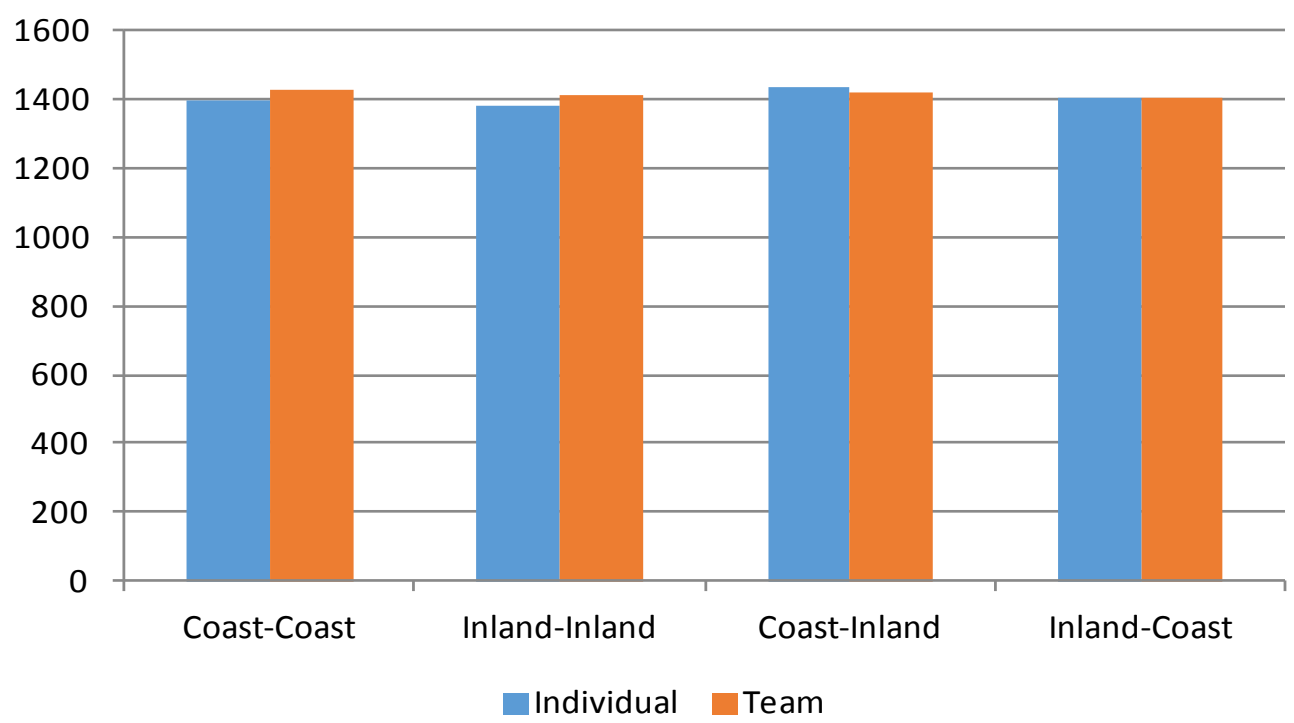

Figure 5a. Subjects’ mean payoffs per period

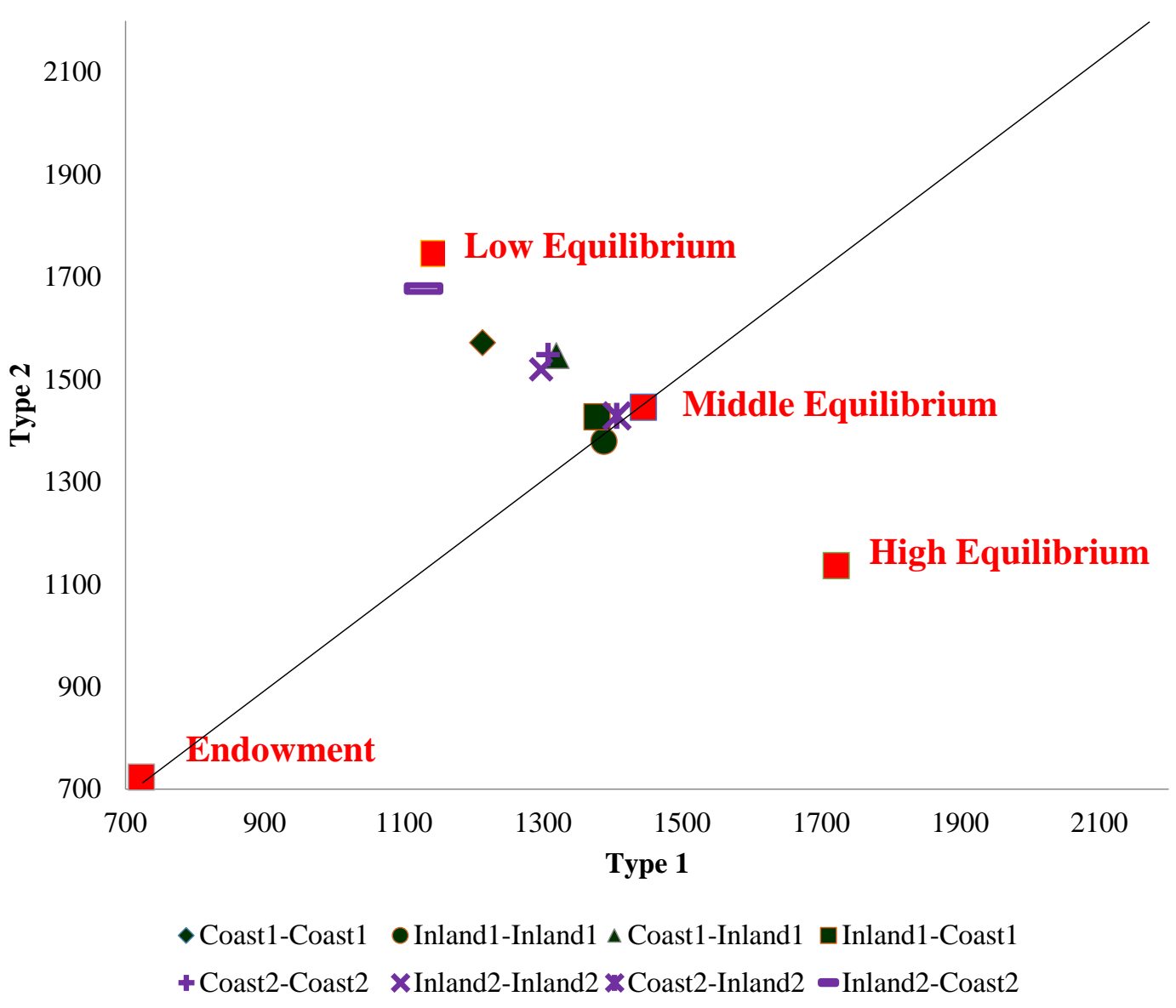

Figure 5b. Subjects' mean payoffs per period separated by subjects' types 


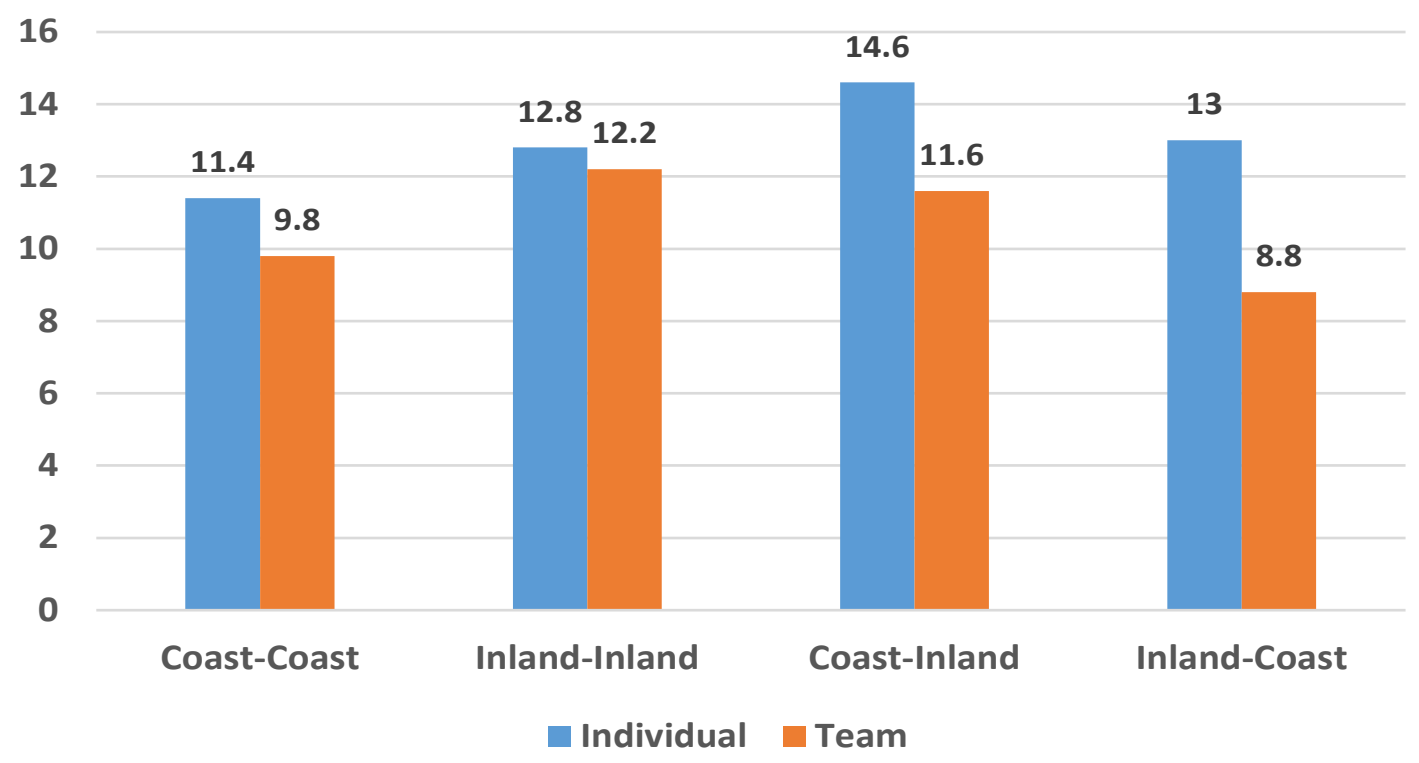

Figure 6. Average number of trades per period 
Table 1. Theoretical Predictions about Discrete Equilibria

\begin{tabular}{|c|c|c|c|c|c|c|}
\hline & \multicolumn{2}{|c|}{ Allocation } & & & \multicolumn{2}{c|}{ Payoff } \\
\hline & $\begin{array}{c}\text { Type } 1 \\
(\mathrm{x} 1, \mathrm{y} 1)\end{array}$ & $\begin{array}{c}\text { Type } 2 \\
(\mathrm{x} 2, \mathrm{y} 2)\end{array}$ & Price & $\begin{array}{c}\text { Walrasian } \\
\text { Stability }\end{array}$ & $\begin{array}{c}\text { Type } 1 \\
\mathrm{U} 1\end{array}$ & $\begin{array}{c}\text { Type 2 } \\
\text { U2 }\end{array}$ \\
\hline A1 & $(7,8)$ & $(23,22)$ & 0.39 & stable & 1091 & 1745 \\
\hline A2 & $(7,9)$ & $(23,21)$ & 0.44 & stable & 1143 & 1745 \\
\hline A3 & $(8,9)$ & $(22,21)$ & 0.47 & stable & 1143 & 1739 \\
\hline B1 & $(12,15)$ & $(18,15)$ & 1.08 & unstable & 1445 & 1445 \\
\hline B2 & $(12,16)$ & $(18,14)$ & 1.15 & unstable & 1445 & 1395 \\
\hline C1 & $(16,20)$ & $(14,10)$ & 2.11 & stable & 1722 & 1136 \\
\hline C2 & $(16,21)$ & $(14,9)$ & 2.22 & stable & 1669 & 1136 \\
\hline
\end{tabular}

Table 2. Time schedule of the experiment

\begin{tabular}{|c|c|c|}
\hline \multirow{2}{*}{ AM } & 9/21/2011 & \multicolumn{1}{|c|}{$9 / 22 / 2011$} \\
\cline { 2 - 3 } & Coast1-Coast1 session: 12 subjects & Coast1-Inland1 session: 12 subjects \\
\hline \multirow{2}{*}{ PM } & Inland1-Inland1 session: 12 subjects & Inland1-Coast1 session: 12 subjects \\
\cline { 2 - 3 } & Coast2-Coast2 session: 24 subjects & Coast2-Inland2 session: 24 subjects \\
\cline { 2 - 3 } & Inland2-Inland2 session: 24 subjects & Inland2-Coast2 session: 24 subjects \\
\hline
\end{tabular}

Notes: The roles of type 1 and type 2 that subjects played are indicated before and after the hyphen, respectively. Coast and Inland refer to the hometowns of subjects locate in coastal and inland areas, respectively. The numbers of 1 and 2 in the sessions name refer to the individual and team treatments, respectively. For example, Coast2-Inland2 session means subjects from coastal areas played the role of type 1 and subjects from inland areas played the role of type 2 in the team treatment.

Table 3. Mean trading ratios of $\mathrm{Y}$ to $\mathrm{X}$ (standard deviation in parentheses)

\begin{tabular}{|l|l|l|l|l|l|}
\hline \multicolumn{2}{|l|}{} & Coast-Coast & Inland-Inland & Coast-Inland & Inland-Coast \\
\hline Individual & Period 1 & $0.850(0.793)$ & $1.228(0.422)$ & $0.835(0.257)$ & $1.136(0.901)$ \\
\hline & Period 2 & $0.760(0.292)$ & $0.949(0.277)$ & $0.829(0.218)$ & $1.003(0.282)$ \\
\hline & Period 3 & $0.766(0.173)$ & $0.992(0.316)$ & $0.888(0.137)$ & $0.968(0.186)$ \\
\hline & Period 4 & $0.770(0.240)$ & $1.008(0.145)$ & $0.835(0.141)$ & $0.941(0.186)$ \\
\hline & Period 5 & $0.630(0.079)$ & $0.961(0.191)$ & $0.805(0.147)$ & $0.903(0.228)$ \\
\hline Team & Period 1 & $0.801(0.370)$ & $0.835(0.370)$ & $1.007(0.293)$ & $0.483(0.254)$ \\
\hline & Period 2 & $0.784(0.254)$ & $0.752(0.234)$ & $1.082(0.320)$ & $0.455(0.120)$ \\
\hline & Period 3 & $0.832(0.310)$ & $0.906(0.264)$ & $1.036(0.111)$ & $0.448(0.066)$ \\
\hline & Period 4 & $0.732(0.179)$ & $0.834(0.136)$ & $1.065(0.098)$ & $0.463(0.021)$ \\
\hline & Period 5 & $0.664(0.134)$ & $0.800(0.169)$ & $1.051(0.073)$ & $0.454(0.023)$ \\
\hline
\end{tabular}


Table 4. Wilcoxon rank sum test for trading ratios of $\mathbf{Y}$ to $\mathrm{X}$ (Individual versus Team)

\begin{tabular}{|l|c|c|c|c|c|l|l|l|}
\hline & \multicolumn{2}{|l|}{ Coast-Coast } & \multicolumn{2}{l|}{ Inland-Inland } & \multicolumn{2}{l|}{ Coast-Inland } & \multicolumn{2}{l|}{ Inland-Coast } \\
\cline { 2 - 10 } & $z$ value & $p$ value & $z$ value & $p$ value & $z$ value & $p$ value & $z$ value & $p$ value \\
\hline Period 1 & -0.530 & 0.5963 & 2.056 & 0.0398 & -1.675 & 0.0939 & 2.800 & 0.0051 \\
\hline Period 2 & -0.535 & 0.5928 & 2.199 & 0.0279 & -2.633 & 0.0085 & 4.077 & 0.0000 \\
\hline Period 3 & -0.205 & 0.8374 & 1.868 & 0.0617 & -2.802 & 0.0051 & 4.181 & 0.0000 \\
\hline Period 4 & 0.191 & 0.8482 & 2.627 & 0.0086 & -3.127 & 0.0018 & 3.514 & 0.0004 \\
\hline Period 5 & -0.826 & 0.4091 & 2.253 & 0.0243 & -3.494 & 0.0005 & 3.253 & 0.0011 \\
\hline
\end{tabular}

Table 5. Wilcoxon rank sum test for payoffs (Individual versus Team)

\begin{tabular}{|c|c|c|c|c|c|c|c|c|}
\hline & \multicolumn{2}{|l|}{ Coast-Coast } & \multicolumn{2}{l|}{ Inland-Inland } & \multicolumn{2}{l|}{ Coast-Inland } & \multicolumn{2}{l|}{ Inland-Coast } \\
\cline { 2 - 10 } & $z$ value & $p$ value & $z$ value & $p$ value & $z$ value & $p$ value & $z$ value & $p$ value \\
\hline Type 1 & -1.121 & 0.2623 & 1.441 & 0.1495 & -2.722 & 0.0065 & 2.887 & 0.0039 \\
\hline Type 2 & 0.480 & 0.6310 & -2.420 & 0.0163 & 2.082 & 0.0374 & -2.882 & 0.0039 \\
\hline
\end{tabular}

Table 6. The average amounts of both commodities $X$ and $Y$ exchanged per trade

\begin{tabular}{|l|l|l|}
\hline & Individual & Team \\
\hline Subjects from the same areas & 13.3833 & 14.1636 \\
\hline Subjects from different areas & 11.9130 & 15.2647 \\
\hline
\end{tabular}

